\title{
A Novel Fluorogenic Transformation: Development of an Optical Probe for Coenzyme Q
}

\author{
Supporting Information
}

\author{
Matthew S. Tremblay and Dalibor Sames* \\ Department of Chemistry, Columbia University, New York, NY 10027
}

\author{
Part I: Synthetic Methods \\ Part II: Lactonization \\ Part III: Reduction Assays \\ Part IV: ${ }^{1}$ H NMR for 3a-c, 4a-c, 5a-c \\ Part V: Selected Photophysical Data for Coumarins 5a-c
}

\section{General}

All manipulations of air and/or water sensitive compounds were performed using standard Schlenk techniques. Nuclear Magnetic Resonance spectra were recorded at 300 $\mathrm{K}$ (unless otherwise noted) on Bruker 300 or 400 or 500 Fourier transform NMR spectrometers. Unless otherwise noted, spectra were taken at $300 \mathrm{~K}$ in $\mathrm{MeOH}-d_{4}$ with the proton $(\delta 3.30)$ or carbon $(\delta 49.0)$ as the reference, in $\mathrm{CHCl}_{3}-d_{1}$ with the proton $(\delta 7.26)$ or carbon $(\delta 77.0)$ as the reference, or in DMSO- $d_{6}$ with the proton $(\delta 2.49)$ or carbon $(\delta$ $39.5)$ as the reference. Flash chromatography was performed on SILICYCLE silica gel (230-400 mesh). Low resolution mass spectra were recorded on a JEOL LCmate (ionization mode: APCI+); high resolution mass spectra were obtained on a JMS_HX110 $\mathrm{HF}$ mass spectrometer (ionization mode: $\mathrm{FAB}+$ ). All chemicals were purchased from Sigma-Aldrich, Acros, or Strem and used as received unless otherwise noted. All solvents were passed through a column of alumina under an argon atmosphere and used without further purification. Ultraviolet spectra were measured on a Molecular Devices SPECTRAmax Plus 384 UV-Visible spectrophotometer operated through a Dell Pentium PC by SOFTmax software. Fluorescence measurements were taken on a Jobin Yvon Fluorolog fluorescence spectrofluorometer. $\mathrm{HPLC}$ was performed on an Xterra $\mathrm{RP}_{18}$ $5 \mu \mathrm{m}$ column $(4.6 \times 150 \mathrm{~mm})$ with a Waters 600 Controller; fractions were detected with a Waters 2487 Dual $\lambda$ Absorbance Detector and data was analyzed using OpenLynx software. 


\section{Part I: Synthetic Methods}
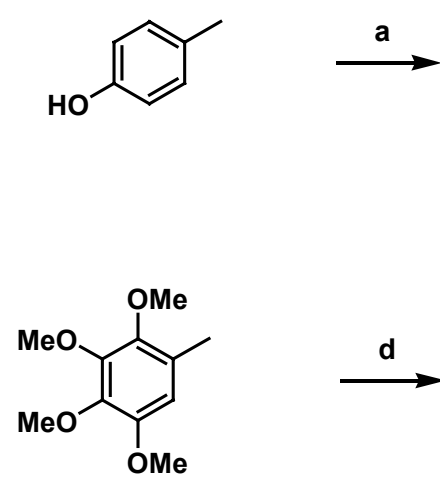

III<smiles>Cc1cc(Br)c(O)c(Br)c1Br</smiles>

I<smiles>COc1c(C)c(Br)c(OC)c(OC)c1OC</smiles>

IV
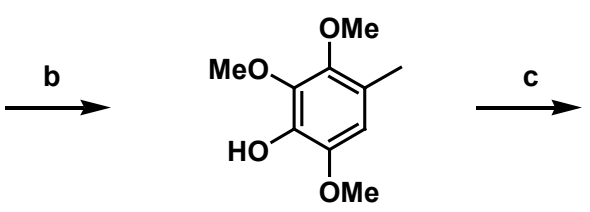

II

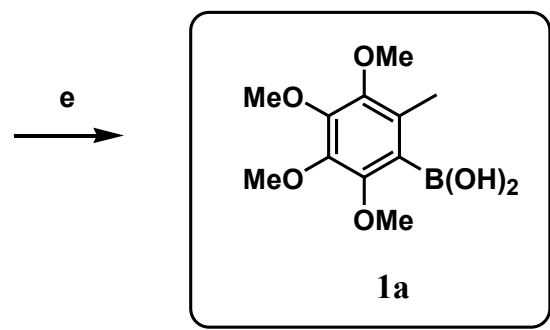

a. $\mathrm{Br}_{2}$ (3 eq.), $\mathrm{Fe}^{0}, \mathrm{CHCl}_{3}, \mathrm{RT}, 4 \mathrm{hrs}, 88 \%$. b. $\mathrm{NaOMe}, \mathrm{CuCN}, \mathrm{DME} / \mathrm{MeOH}, \mathrm{Me}_{2} \mathrm{CO}_{3}, 80^{\circ} \mathrm{C}, 24 \mathrm{hrs}, 66 \%$. c. $\mathrm{Mel}$, $\mathrm{K}_{2} \mathrm{CO}_{3}$, acetone, RT, 3hrs. d. N-bromosuccinimde, $\mathrm{CH}_{2} \mathrm{Cl}_{2}, \mathrm{RT}, 57 \%$ for two steps. e. i) $n$-BuLi, hexanes/THF, $-78^{\circ} \mathrm{C}$, 1.5hrs ii) $\mathrm{B}(\mathrm{OMe})_{3}$ (neat), $-78^{\circ} \mathrm{C}$ to $\mathrm{RT}$, $20 \mathrm{hrs}$.

Scheme S1. Synthesis of boronic acid 1a.

\section{2,3,6-tribromo-4-methylphenol (I). ${ }^{1}$}

To a solution of 4-methylphenol [Aldrich] (10.80g, 100mmol, 1 eq.) and Fe powder $(0.400 \mathrm{~g}, 7 \mathrm{mmol}, 0.07$ eq. $)$ in $\mathrm{CHCl}_{3}(70 \mathrm{~mL})$ under argon was added $\mathrm{Br}_{2}(16 \mathrm{~mL}, 312$ mmol, 3.12 eq.) slowly over 2 hours via syringe. The dark red mixture was allowed to stir for 4 hours at RT, at which time it was washed three times with a saturated aqueous $\mathrm{Na}_{2} \mathrm{SO}_{3}$ solution, washed once with brine, and dried with $\mathrm{MgSO}_{4}$. The crude light yellow solid was recrystallized from hexanes to give the title compound as white needles (30.65g, 88\%). ${ }^{1} \mathrm{H}$ NMR $\left(\mathrm{CDCl}_{3}, 300 \mathrm{MHz}\right): \delta 7.38$ (s, 1H), $5.88(\mathrm{~s}, 1 \mathrm{H}), 2.41$ (s, 3H); MS (HR-FAB+): Calc'd for $\mathrm{C}_{7} \mathrm{H}_{5} \mathrm{Br}_{3} \mathrm{O} 341.7890$, measured 341.7890.

\section{2,3,6-trimethoxy-4-methylphenol (II). ${ }^{1}$}

To a stirred solution of $\mathrm{NaOMe}(18.9 \mathrm{~g}, 350 \mathrm{mmol}, 10$ eq.) in dry $\mathrm{MeOH}(30 \mathrm{~mL})$ under argon at RT was added DME (90mL), $\mathrm{Me}_{2} \mathrm{CO}_{3}(17.4 \mathrm{~mL}, 193 \mathrm{mmol}, 5.5$ eq.), and $\mathrm{CuCN}$ (5.0g, 56mmol, 1.6 eq.). The mixture was heated to $60^{\circ} \mathrm{C}$ and a solution of 2,3,6tribromo-4-methylphenol (12.0 g, 35mmol, 1 eq.) in DME $(30 \mathrm{~mL})$ was added via cannula. The green/blue heterogeneous mixture was heated at $80^{\circ} \mathrm{C}$ in the dark. The reaction progress was monitored by ${ }^{1} \mathrm{H} \mathrm{NMR}$, and additional $\mathrm{NaOMe}, \mathrm{CuCN}$, and $\mathrm{Me}_{2} \mathrm{CO}_{3}$ were added as necessary. The reaction was complete after 5 days, at which time the mixture was cooled to RT, quenched with aqueous $10 \%$ citric acid $(150 \mathrm{~mL})$, diluted with EtOAc, and filtered. The organic phase was separated and dried with $\mathrm{MgSO}_{4}$. The crude oil was purified by flash chromatography $(10 \%$ EtOAc/hexanes) to give the title

\footnotetext{
${ }^{1}$ Keinan, E., Eren, D. J. Org. Chem. 1987, 52, $3872-3875$.
} 
compound as a light yellow oil $(4.57 \mathrm{~g}, 66 \%) .{ }^{1} \mathrm{H} \mathrm{NMR}\left(\mathrm{CDCl}_{3}, 300 \mathrm{MHz}\right): \delta 6.42(\mathrm{~s}$, $1 \mathrm{H}), 5.59(\mathrm{~s}, 1 \mathrm{H}), 3.93(\mathrm{~s}, 3 \mathrm{H}), 3.83(\mathrm{~s}, 3 \mathrm{H}), 3.79(\mathrm{~s}, 3 \mathrm{H}), 2.20(\mathrm{~s}, 3 \mathrm{H}) .{ }^{13} \mathrm{C} \mathrm{NMR}(75$ $\mathrm{MHz}): \delta 145.2,143.2,140.4,136.9,121.0,107.8,60.7,60.4,56.2,15.4$. MS (LR-APCI): Calc'd for $\mathrm{C}_{10} \mathrm{H}_{14} \mathrm{O}_{4}$ 198.09, measured 198.21.

\section{1,2,3,4-Tetramethoxy-5-methylbenzene (III).}

To a stirred solution of 2,3,6-trimethoxy-4-methylphenol $(2.45 \mathrm{~g}, 12.4 \mathrm{mmol}$, 1eq.) and $\mathrm{K}_{2} \mathrm{CO}_{3}(5.12 \mathrm{~g}, 37.1 \mathrm{mmol}, 3$ eq.) in acetone $(40 \mathrm{~mL})$ was added $\mathrm{MeI}(4.6 \mathrm{~mL}, 74.2 \mathrm{mmol}$, 6eq.). The mixture was stirred at reflux for $6 \mathrm{hrs}$, after which it was cooled to RT and filtered. The acetone was removed by rotary evaporation, and the crude material was redissolved in $\mathrm{CH}_{2} \mathrm{Cl}_{2}$, filtered, and dried with $\mathrm{MgSO}_{4}$. The crude oil was used without further purification. ${ }^{1} \mathrm{H} \mathrm{NMR}\left(\mathrm{CDCl}_{3}, 300 \mathrm{MHz}\right): \delta 6.42(\mathrm{~s}, 1 \mathrm{H}), 3.91(\mathrm{~s}, 3 \mathrm{H}), 3.86(\mathrm{~s}$, $3 \mathrm{H}), 3.79(\mathrm{~s}, 3 \mathrm{H}), 3.76(\mathrm{~s}, 3 \mathrm{H}), 2.21(\mathrm{~s}, 3 \mathrm{H}) .{ }^{13} \mathrm{C}$ NMR $(75 \mathrm{MHz}): \delta 149.0,146.9,145.3$, 140.7, 125.7, 108.2, 61.0, 60.5, 55.9, 15.7. MS (LR-APCI): Calc'd for $\mathrm{C}_{11} \mathrm{H}_{16} \mathrm{O}_{4}$ 212.10, measured 212.08.

\section{1-Bromo-2,3,4,5-tetramethoxy-6-methylbenzene (IV). ${ }^{2}$}

To a stirred solution of 2,3,4,5-tetramethoxytoluene (2.6g, $12.4 \mathrm{mmol}, 1$ eq.) in $\mathrm{CH}_{2} \mathrm{Cl}_{2}$ $(30 \mathrm{~mL})$ was added solid N-bromosuccinimide (NBS) $(2.2 \mathrm{~g}, 12.4 \mathrm{mmol}, 1$ eq.) . The reaction was stirred at $\mathrm{RT}$ under argon for $2 \mathrm{hrs}$, after which time it was washed with $50 \%$ $\mathrm{NaCl} / \mathrm{H}_{2} \mathrm{O}$ and dried with $\mathrm{MgSO}_{4}$. The crude oil was purified by flash chromatography $\left(10 \%\right.$ EtOAc/hexanes) to give the title compound $(2.05 \mathrm{~g}, 57 \%$ for two steps $) .{ }^{1} \mathrm{H}$ NMR $\left(\mathrm{CDCl}_{3}, 300 \mathrm{MHz}\right): \delta 3.89(\mathrm{~s}, 6 \mathrm{H}), 3.82(\mathrm{~s}, 3 \mathrm{H}), 3.77(\mathrm{~s}, 3 \mathrm{H}), 2.28(\mathrm{~s}, 3 \mathrm{H}) .{ }^{13} \mathrm{C} \mathrm{NMR}(75$ $\mathrm{MHz}): \delta 148.3,147.2,146.3,145.5,127.2,114.2,61.3,61.0,60.7,15.9$. MS (LR-APCI): Calc'd for $\mathrm{C}_{11} \mathrm{H}_{15} \mathrm{Br} \mathrm{O}_{4} 290.02$ / 292.01 , measured 290.08 / 292.08.

\section{$\left(2,3,4,5\right.$-tetramethoxy-6-methyl)phenylboronic acid (1a). ${ }^{3}$}

To a stirred solution of 1-Bromo-2,3,4,5-tetramethoxy-6-methyl-benzene $(1.0 \mathrm{~g}$, $3.45 \mathrm{mmol}, 1$ eq.) in THF $(9 \mathrm{~mL})$ at $-78^{\circ} \mathrm{C}$ was added $n$ BuLi $(1.6 \mathrm{M}$ in hexanes, $2.35 \mathrm{~mL}$, $3.80 \mathrm{~mL}, 1.1$ eq.) dropwise. The mixture was stirred at $-78^{\circ} \mathrm{C}$ for 1.5 hours, at which time $\mathrm{B}(\mathrm{OMe})_{3}(0.64 \mathrm{~mL}, 5.2 \mathrm{mmol}, 1.5 \mathrm{eq})$ was added at via syringe. The mixture was allowed to warm to RT and stirred for an additional 12 hours, after which time the reaction was cooled to $0^{\circ} \mathrm{C}$, quenched with $1 \mathrm{~N} \mathrm{HCl}(5 \mathrm{~mL})$, and extracted into $\mathrm{CH}_{2} \mathrm{Cl}_{2}$. After evaporation, the crude oil was used immediately without further purification for the synthesis of $\mathbf{2 a}$.

\footnotetext{
${ }^{2}$ Jung, Y-S., Joe, B-Y, Seong, C-M., Park, N-S. Bull. Korean Chem. Soc. 2000, 21, 463 - 464.

${ }^{3}$ a) Fukuyama, Y., Kiriyama, Y., Kodama, M. Tetrahedron Lett. 1993, 34, 7637 - 7638.
} 


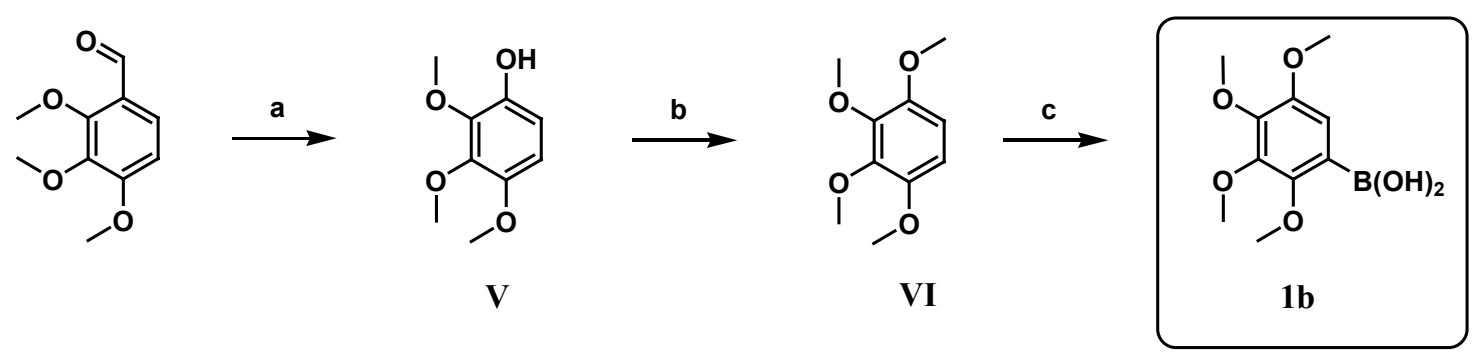

a. $\mathrm{H}_{2} \mathrm{O}_{2}, \mathrm{MeOH} / \mathrm{H}_{2} \mathrm{SO}_{4}, \mathrm{RT}, 1 \mathrm{hr}, 74 \%$. b. Mel, $\mathrm{K}_{2} \mathrm{CO}_{3}$, acetone, $\mathrm{RT}$, 6hrs, $89 \%$. c. i) $n$-BuLi, hexanes/THF, RT, $1.5 \mathrm{hrs}$ ii) $\mathrm{B}(\mathrm{OMe})_{3}$ (neat), $-78^{\circ} \mathrm{C}$ to $\mathrm{RT}, 2 \mathrm{hrs}$ iii) $1 \mathrm{~N} \mathrm{HCl}, 0^{\circ} \mathrm{C}, 20 \mathrm{~min}$.

Scheme S2. Synthesis of boronic acid $\mathbf{1 b .}$

2,3,4-trimethoxyphenol (V). To a solution of 2,3,4-trimethoxy-benzaldehyde [Aldrich] (5.88g, 30mmol, $1.0 \mathrm{eq})$ in $\mathrm{H}_{2} \mathrm{SO}_{4} / \mathrm{MeOH}(1: 100 \mathrm{v} / \mathrm{v}, 60 \mathrm{~mL})$ at $0^{\circ} \mathrm{C}$ under an atmosphere of argon was added $30 \%$ aqueous $\mathrm{H}_{2} \mathrm{O}_{2}(4.80 \mathrm{~mL}, 38.4 \mathrm{mmol}, 1.15 \mathrm{eq})$. After $1 \mathrm{hr}$, the reaction was diluted with $\mathrm{Et}_{2} \mathrm{O}(150 \mathrm{~mL})$, washed successively with $\mathrm{H}_{2} \mathrm{O}(75 \mathrm{~mL})$ and saturated aqueous $\mathrm{NaCl}(75 \mathrm{~mL})$, dried over $\mathrm{MgSO}_{4}$, filtered, and the solvent was removed under reduced pressure. The crude brown oil was purified by flash chromatography (silica, 10\% EtOAc / hexanes) to give the title compound as a clear oil (4.10g, 74\%). ${ }^{1} \mathrm{H} \mathrm{NMR}\left(\mathrm{CDCl}_{3}, 300 \mathrm{MHz}\right): \delta 6.63(\mathrm{~d}, J=8.9 \mathrm{~Hz}, 1 \mathrm{H}), 6.55(\mathrm{~d}, J=9.0 \mathrm{~Hz}$, $1 \mathrm{H}), 5.40(\mathrm{~s}, 1 \mathrm{H}), 3.96(\mathrm{~s}, 3 \mathrm{H}), 3.90(\mathrm{~s}, 3 \mathrm{H}), 3.82(\mathrm{~s}, 3 \mathrm{H})$. MS (LR-APCI): Calc'd for $\mathrm{C}_{9} \mathrm{H}_{12} \mathrm{O}_{4}$ 184.07, measured 184.02.

Tetramethoxybenzene (VI). To a stirred solution of 6 (4.10g, 22.3mmol, 1.0 eq.) and $\mathrm{K}_{2} \mathrm{CO}_{3}(9.2 \mathrm{~g}, 66.9 \mathrm{mmol}, 3.0$ eq.) in acetone $(50 \mathrm{~mL})$ was added $\mathrm{MeI}(8.3 \mathrm{~mL}, 134 \mathrm{mmol}$, 6.0 eq.). The mixture was stirred at reflux for $6 \mathrm{hrs}$, after which it was cooled to RT and filtered. The acetone was removed by rotary evaporation, and the crude material was redissolved in $\mathrm{CH}_{2} \mathrm{Cl}_{2}$, filtered, and dried with $\mathrm{MgSO}_{4}$. The crude white solid was recrystallized from hexanes to give long colorless needles $(3.95 \mathrm{~g}, 89 \%) .{ }^{1} \mathrm{H} \mathrm{NMR}$ $\left(\mathrm{CDCl}_{3}, 300 \mathrm{MHz}\right): \delta 6.57(\mathrm{~s}, 2 \mathrm{H}), 3.90(\mathrm{~s}, 3 \mathrm{H}), 3.81(\mathrm{~s}, 3 \mathrm{H}) .{ }^{13} \mathrm{C} \mathrm{NMR}\left(\mathrm{CDCl}_{3}, 75 \mathrm{MHz}\right)$ : $\delta$ 147.4, 143.1, 106.2, 61.1, 56.3. MS (LR-APCI): Calc'd for $\mathrm{C}_{10} \mathrm{H}_{14} \mathrm{O}_{4}$ 198.09, measured 198.15 .

2,3,4,5-tetramethoxyphenylboronic acid (1b). To a stirred solution of 7 (500mg, $2.5 \mathrm{mmol}, 1.0 \mathrm{eq})$ in THF $(5 \mathrm{~mL})$ at RT under positive pressure of argon, $n$-BuLi $(1.6 \mathrm{M}$ in hexane; $1.74 \mathrm{~mL}, 2.78 \mathrm{mmol}, 1.1 \mathrm{eq}$ ) was added dropwise (light yellow precipitate after complete addition). The mixture was stirred for 15 minutes at RT, then cooled to $-78^{\circ} \mathrm{C}$ under positive pressure of argon. $\mathrm{B}(\mathrm{OMe})_{3}(1.67 \mathrm{~mL}, 15 \mathrm{mmol}, 6 \mathrm{eq})$ was added and the cloudy yellow solution became cloudy white, and, after warming slowly to RT, became clear and colorless. After $3 \mathrm{hrs}$ at RT, the solution was cooled to $0^{\circ} \mathrm{C}$ and aqueous $\mathrm{HCl}$ $(1.0 \mathrm{M}, 10 \mathrm{~mL})$ was added and the reaction was allowed to warm to RT. After $2 \mathrm{hrs}$, the solution was diluted with $\mathrm{Et}_{2} \mathrm{O}(50 \mathrm{~mL})$, washed successively with aqueous $\mathrm{HCl}(1.0 \mathrm{M}$, $20 \mathrm{~mL})$, saturated aqueous $\mathrm{NaCl}(20 \mathrm{~mL})$, dried over $\mathrm{MgSO}_{4}$, filtered, and evaporated and the clear oil was used immediately without further purification for the synthesis of $\mathbf{2 b}, \mathbf{c}$. 
<smiles>[R]c1c(OC)c(OC)c(OC)c(OC)c1OC</smiles>

1a, b

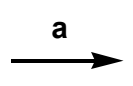<smiles>[R]c1c([R])c(OC)c(OC)c(OC)c1OC</smiles>

2a-c
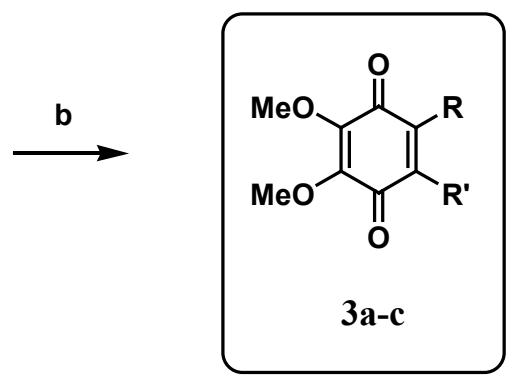

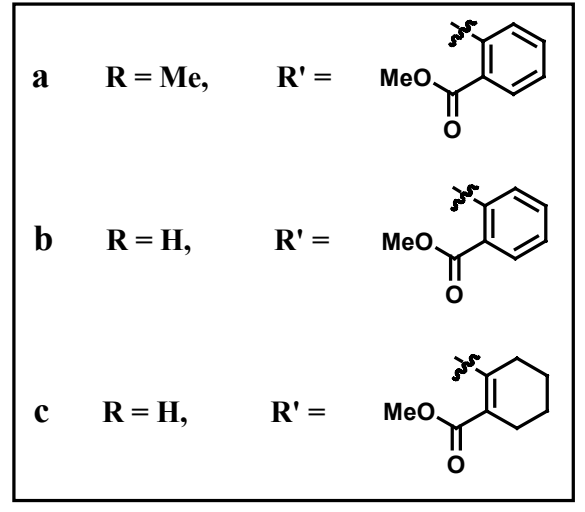

Reagents/Conditions: a. Br-R', $\mathrm{Pd}_{2} \mathrm{dba}_{3}$, DPEPhos, mol. sieves, $\mathrm{PhMe}, 110^{\circ} \mathrm{C}, 24 \mathrm{hrs}, 50-90 \%$. b. Ceric ammonium nitrate (CAN), $\mathrm{MeCN} / \mathrm{H}_{2} \mathrm{O}, 0^{\circ} \mathrm{C}, 2$ - 6hrs, 20 - 70\%.

Scheme S3. Synthesis of Quinone Probes 3a-c.

\section{2',3',4',5'-Tetramethoxy-6'methyl-biphenyl-2-carboxylic acid methyl ester (2a)}

The crude boronic acid ( $3.45 \mathrm{mmol}, 2$ eq.) was combined with $\mathrm{K}_{3} \mathrm{PO}_{4}(1.09 \mathrm{~g}, 10.4 \mathrm{mmol}$, 3 eq.), $\mathrm{Pd}_{2} \mathrm{dba}_{3}$ (155mg, $0.35 \mathrm{mmol}, 0.1$ eq.), DPEPhos (112mg, $0.35 \mathrm{mmol}, 0.1$ eq.), and $4 \AA$ molecular sieves in a flame dried Schlenk flask, which was purged and backfilled with argon. PhMe $(8.6 \mathrm{~mL})$ and methyl 2-bromo-benzoate $(0.259 \mathrm{~mL}, 1.73 \mathrm{mmol}, 1$ eq.) were then added and the mixture was stirred at $110^{\circ} \mathrm{C}$ for 24 hours. The crude reaction mixture was cooled to RT, diluted with $\mathrm{Et}_{2} \mathrm{O}$ and filtered through a plug of silica gel. The crude oil was purified by flash chromatography ( $5 \%$ EtOAc/hexanes) to give the title compound as a pale yellow oil $(0.395 \mathrm{~g}, 66 \%): .{ }^{1} \mathrm{H} \mathrm{NMR}\left(\mathrm{CDCl}_{3}, 300 \mathrm{MHz}\right): \delta 7.98(\mathrm{~d}, J$ $=7.7 \mathrm{~Hz}, 1 \mathrm{H}), 7.51(\mathrm{t}, J=7.1 \mathrm{~Hz}, 1 \mathrm{H}), 7.40(\mathrm{t}, J=7.4 \mathrm{~Hz}, 1 \mathrm{H}), 7.19(\mathrm{~d}, J=7.9 \mathrm{~Hz}, 1 \mathrm{H})$, $3.98(\mathrm{~s}, 3 \mathrm{H}), 3.91(\mathrm{~s}, 3 \mathrm{H}), 3.82(\mathrm{~s}, 3 \mathrm{H}), 3.64(\mathrm{~s}, 3 \mathrm{H}), 3,51(\mathrm{~s}, 3 \mathrm{H}), 1.85(\mathrm{~s}, 3 \mathrm{H}) .{ }^{13} \mathrm{C} \mathrm{NMR}$ (75 MHz): $\delta$ 167.6, 147.5, 146.4, 145.9, 144.3, 138.2, 131.4, 130.8, 130.1, 129.4, 128.0, 127.1, 124.5, 61.1, 60.6, 60.5, 51.7, 12.9. MS (LR-APCI): Calc'd for $\mathrm{C}_{19} \mathrm{H}_{22} \mathrm{O}_{6} 346.14$, measured 346.36 .

2',3',4',5'-Tetramethoxy-biphenyl-2-carboxylic acid methyl ester (2b).

This compound was prepared from crude boronic acid $\mathbf{1 b}$ using the same conditions as those used for the preparation of 2a. Yellow oil $(68 \%)$ : ${ }^{1} \mathrm{H} \mathrm{NMR}\left(\mathrm{CDCl}_{3}, 300 \mathrm{MHz}\right): \delta$ $7.86(\mathrm{~d}, J=7.7 \mathrm{~Hz}, 1 \mathrm{H}), 7.52(\mathrm{t}, J=7.5,1 \mathrm{H}), 7.40(\mathrm{t}, J=7.5 \mathrm{~Hz}, 1 \mathrm{H}), 7.35(\mathrm{~d}, J=8.0 \mathrm{~Hz}$, $1 \mathrm{H}), 6.53(\mathrm{~s}, 1 \mathrm{H}), 3.94(\mathrm{~s}, 6 \mathrm{H}), 3.84(\mathrm{~s}, 3 \mathrm{H}), 3.68(\mathrm{~s}, 3 \mathrm{H}), 3.45(\mathrm{~s}, 3 \mathrm{H}),{ }^{13} \mathrm{C}$ NMR $\left(\mathrm{CDCl}_{3}, 125 \mathrm{MHz}\right): \delta 168.5,149.1,146.7,144.4,142.3,138.2,131.48,131.2,131.1$, 129.7, 129.6, 127.2, 107.6, 61.4, 61.0, 60.6, 56.1, 51.8. MS (LR-APCI): Calc'd for $\mathrm{C}_{18} \mathrm{H}_{20} \mathrm{O}_{6} 332.13$, measured 331.89 . 
2-(2,3,4,5-Tetramethoxy-phenyl)-cyclohex-1-enecarboxylic acid methyl ester (2c).

This compound was prepared from crude boronic acid $\mathbf{1 b}$ using the same conditions as those used for the preparation of 2a except that 2-bromo-cyclohex-1-enecarboxylic acid methyl ester ${ }^{4}$ was used in place of methyl 2-bromobenzoate. ${ }^{1} \mathrm{H} \mathrm{NMR}\left(\mathrm{CDCl}_{3}, 400 \mathrm{MHz}\right)$ : $\delta 6.23(\mathrm{~s}, 1 \mathrm{H}), 3.87(\mathrm{~s}, 3 \mathrm{H}), 3.85(\mathrm{~s}, 3 \mathrm{H}), 3.74(\mathrm{~s}, 3 \mathrm{H}), 3.71(\mathrm{~s}, 3 \mathrm{H}), 3.41(\mathrm{~s}, \mathrm{H}), 2.40(\mathrm{bs}$, 2H), 2.35 (bs, 2H), $1.70(\mathrm{~s}, 4 \mathrm{H}) .{ }^{13} \mathrm{C} \mathrm{NMR}\left(\mathrm{CDCl}_{3}, 100 \mathrm{MHz}\right): \delta 169.0,148.7,146.5$, $143.7,143.4,141.5,131.7,127.9,106.3,61.1,61.0,56.3,56.2,51.0,32.4,26.5,22.5$, 22.1. MS (LR-APCI): Calc'd for $\mathrm{C}_{18} \mathrm{H}_{24} \mathrm{O}_{6} 336.16$, measured 336.39.

2-(4,5-Dimethoxy-2-methyl-3,6-dioxo-cyclohexa-1,4-dienyl)-benzoic acid methyl ester (3a). ${ }^{5}$

To a stirred solution of 2',3',4',5'-Tetramethoxy-6'-methyl-biphenyl-2-carboxylic acid methyl ester (128mg, $0.37 \mathrm{mmol}, 1$ eq.) in $\mathrm{MeCN} / \mathrm{H}_{2} \mathrm{O}(7: 3)(5 \mathrm{~mL})$ at $0^{\circ} \mathrm{C}$ under argon was added cerric ammonium nitrate $(\mathrm{CAN})\left(507 \mathrm{mg}, 0.93 \mathrm{mmol}, 2.5\right.$ eq.) in $\mathrm{MeCN} / \mathrm{H}_{2} \mathrm{O}$ $(1: 1)(1 \mathrm{~mL})$ dropwise. The mixture was allowed to warm to RT and stirred for 1 hour, after which it was diluted with $\mathrm{Et}_{2} \mathrm{O}$, washed with brine, and dried with $\mathrm{MgSO}_{4}$. The crude oil was purified by flash chromatography (10\% EtOAc/hexanes) to give the title compound as a yellow solid (80mg, 68\%): ${ }^{1} \mathrm{H} \mathrm{NMR}\left(\mathrm{CDCl}_{3}, 300 \mathrm{MHz}\right): \delta 8.09(\mathrm{~d}, J=$ $7.9 \mathrm{~Hz}, 1 \mathrm{H}), 7.57(\mathrm{t}, J=7.4 \mathrm{~Hz}, 1 \mathrm{H}), 7.45(\mathrm{t}, J=7.7 \mathrm{~Hz}, 1 \mathrm{H}), 7.12(\mathrm{~d}, J=7.1 \mathrm{~Hz}, 1 \mathrm{H}), 4.06$ $(\mathrm{s}, 3 \mathrm{H}), 3.97(\mathrm{~s}, 3 \mathrm{H}), 3.77(\mathrm{~s}, 3 \mathrm{H}), 1.80(\mathrm{~s}, 3 \mathrm{H}) .{ }^{13} \mathrm{C}$ NMR $(75 \mathrm{MHz}): \delta 184.5,183.2$, 166.2, 144.9, 144.4, 143.7, 136.6, 135.0, 132.4, 130.6, 130.2, 129.2, 128.7, 61.1, 61.0, 52.1, 13.2. MS (LR-APCI): Calc'd for $\mathrm{C}_{17} \mathrm{H}_{16} \mathrm{O}_{6} 316.09$, measured 316.16.

2-(4,5-Dimethoxy-3,6-dioxo-cyclohexa-1,4-dienyl)-benzoic acid methyl ester (3b).

This compound was prepared from $\mathbf{2} \mathbf{b}$ using the same conditions as those used for the preparation of 3a. ${ }^{1} \mathrm{H} \mathrm{NMR}\left(\mathrm{CDCl}_{3}, 300 \mathrm{MHz}\right): \delta 8.06(\mathrm{dd}, J=7.6 \mathrm{~Hz}, 1.2 \mathrm{~Hz}, 1 \mathrm{H}), 7.57$ $(\mathrm{dt}, J=7.4 \mathrm{~Hz}, 1.4 \mathrm{~Hz}, 1 \mathrm{H}), 7.53(\mathrm{dt}, J=7.7 \mathrm{~Hz}, 1.4 \mathrm{~Hz}, 1 \mathrm{H}), 7.26(\mathrm{dd}, J=7.0 \mathrm{~Hz}, 1.3 \mathrm{~Hz}$, $1 \mathrm{H}), 6.51(\mathrm{~s}, 1 \mathrm{H}), 4.10(\mathrm{~s}, 3 \mathrm{H}), 4.00(\mathrm{~s}, 3 \mathrm{H}), 3.81(\mathrm{~s}, 3 \mathrm{H}) .{ }^{13} \mathrm{C} \mathrm{NMR}(75 \mathrm{MHz}): \delta 185.4$, $183.9,166.8,144.3,143.9,143.3,136.2,135.3,132.1,131.2,129.9,128.6,128.8,61.1$, 61.0, 52.1. MS (LR-APCI): Calc'd for $\mathrm{C}_{16} \mathrm{H}_{14} \mathrm{O}_{6} 302.08$, measured 301.68.

\section{2-(4,5-dimethoxy-3.6-dioxo-cyclohexa-1,4-dienyl)-cyclohex-1-enecarboxylic acid methyl ester (3c).}

This compound was prepared from $2 \mathrm{c}$ using the same conditions as those used for the preparation of 3a. ${ }^{1} \mathrm{H}$ NMR $\left(\mathrm{CDCl}_{3}, 300 \mathrm{MHz}\right): \delta 6.25(\mathrm{~s}, 1 \mathrm{H}), 4.19(\mathrm{~s}, 3 \mathrm{H}), 3.77(\mathrm{~s}, 3 \mathrm{H})$, $3.24(\mathrm{~s}, 3 \mathrm{H}), 2.40(\mathrm{~m}, 2 \mathrm{H}), 2.22(\mathrm{~m}, 2 \mathrm{H}), 1.71(\mathrm{~m}, 4 \mathrm{H}) .{ }^{13} \mathrm{C}$ NMR $(75 \mathrm{MHz}): \delta 183.4$, 181.2, 164.8, 145.1, 144.8, 144.5, 143.5, 135.9, 128.7, 61.2, 61.0, 51.6, 39.0, 34.2, 22.2, 21.8. MS (LR-APCI): Calc'd for $\mathrm{C}_{16} \mathrm{H}_{18} \mathrm{O}_{6} 306.11$, measured 305.57.

\footnotetext{
${ }^{4}$ Prepared in three steps from cyclohexanone: bromo/formylation [Organometallics 2000, 19, 5525 5528]; oxidation [J. Org. Chem. 1979, 44, 1022-1024]; esterification with ethereal diazomethane.

${ }^{5}$ Ohshima, M., Miyoshi, H., Sakamoto, K., Takegami, K., Iwata, J., Kuwabara, K., Iwamura, H., Yagi, T. Biochemistry 1998, 37, 6436-6445.
} 


\section{Synthesis of Quinols 4a-c and Coumarins 5a-c.}

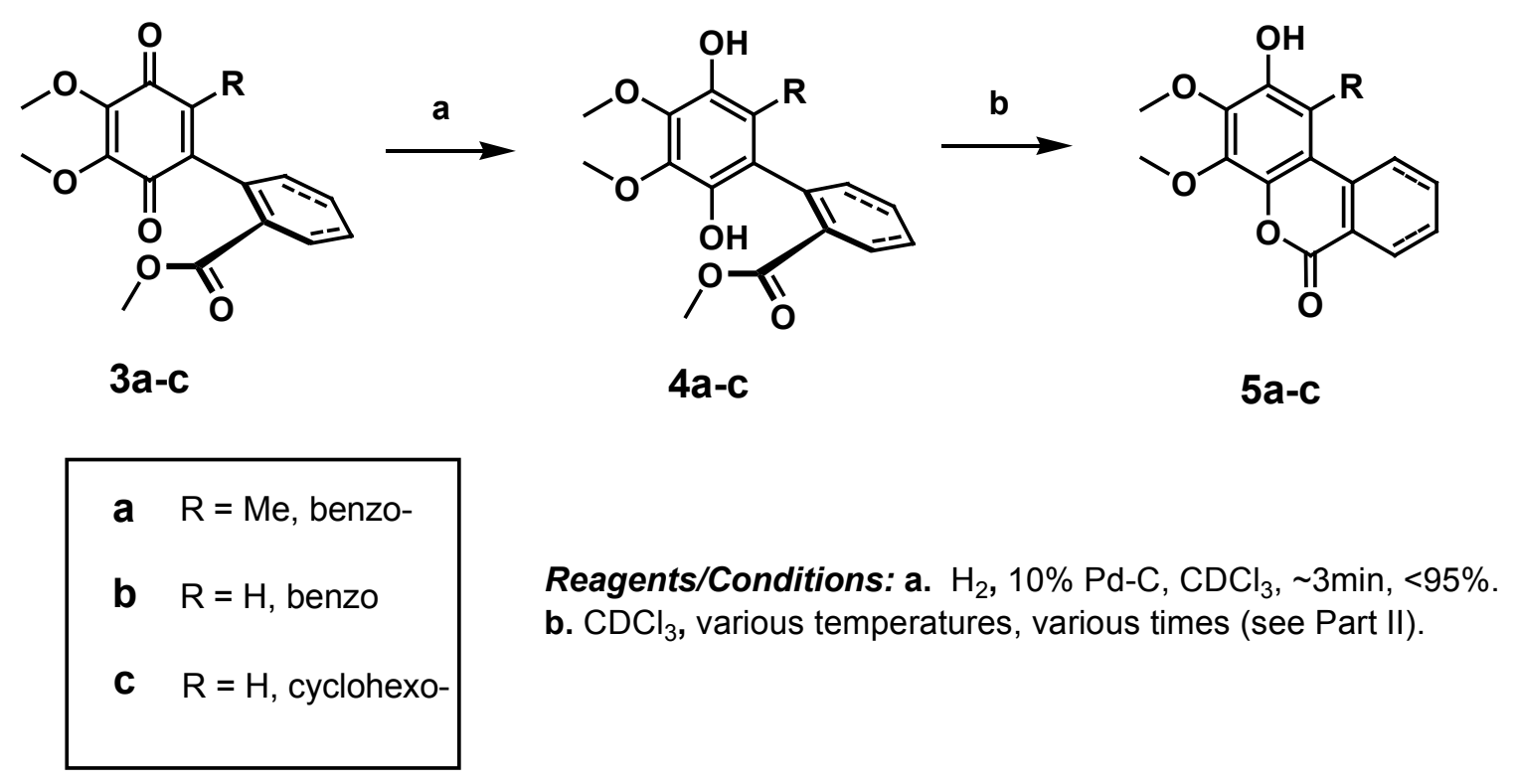

Scheme S4. Synthesis of Quinols 4a-c and Coumarins 5a-c.

2',5'-Dihydroxy-3',4'-dimethoxy-6'methyl-biphenyl-2-carboxylic acid methyl ester (4a). Quinone 3a (31 mg, $0.1 \mathrm{mmol})$ was dissolved in $\mathrm{CDCl}_{3}$ and briefly degassed and refilled with argon. A few grains of $10 \%$ Pd-C were added and the solution was stirred and placed under an atmosphere of $\mathrm{H}_{2}$. After 1-3 minutes, the characteristic red color of the quinone had dissipated and the solution was colorless, at which time it was immediately filtered through celite with $\mathrm{CDCl}_{3}$ as eluent and stored under argon. ${ }^{1} \mathrm{H}$ NMR showed quantitative conversion to the quinol 4a. Reduction could also be achieved by titrating a methanolic solution of the quinone with saturated aqueous $\mathrm{Na}_{2} \mathrm{~S}_{2} \mathrm{O}_{4}$, followed by extraction into ether. ${ }^{1} \mathrm{H}$ NMR $\left(\mathrm{CDCl}_{3}, 400 \mathrm{MHz}\right): \delta 8.00(\mathrm{~d}, J=8.0 \mathrm{~Hz}$, $1 \mathrm{H}), 7.57(\mathrm{t}, J=7.6 \mathrm{~Hz}, 1 \mathrm{H}), 7.44(\mathrm{t}, J=8.0 \mathrm{~Hz}, 1 \mathrm{H}), 7.23(\mathrm{~d}, J=8.0 \mathrm{~Hz}, 1 \mathrm{H}), 5.42(\mathrm{~s}$, $1 \mathrm{H}), 5.10(\mathrm{~s}, 1 \mathrm{H}), 3.99(\mathrm{~s}, 3 \mathrm{H}), 3.92(\mathrm{~s}, 3 \mathrm{H}), 3.68(\mathrm{~s}, 3 \mathrm{H}), 1.87(\mathrm{~s}, 3 \mathrm{H})$.

2',5'-Dihydroxy-3',4'-dimethoxy -biphenyl-2-carboxylic acid methyl ester (4b).

This compound was prepared from $\mathbf{3 b}$ using the same conditions as those used for the preparation of 4a. . ${ }^{1} \mathrm{H} \mathrm{NMR}\left(\mathrm{CDCl}_{3}, 300 \mathrm{MHz}\right): \delta 7.88(\mathrm{dd}, J=7.5 \mathrm{~Hz}, J=1.2 \mathrm{~Hz}, 1 \mathrm{H})$, $7.54(\mathrm{dt}, J=7.5 \mathrm{~Hz}, J=1.6 \mathrm{~Hz}, 1 \mathrm{H}), 7.40(\mathrm{dt}, J=7.8 \mathrm{~Hz}, J=1.5 \mathrm{~Hz}, 1 \mathrm{H}), 7.33(\mathrm{dd}, J=$ $7.5 \mathrm{~Hz}, J=1.7 \mathrm{~Hz}, 1 \mathrm{H}), 6.53(\mathrm{~s}, 1 \mathrm{H}), 5.38(\mathrm{~s}, 1 \mathrm{H}), 5.30(\mathrm{~s}, 1 \mathrm{H}), 3.98(\mathrm{~s}, 3 \mathrm{H}), 3.94(\mathrm{~s}, 3 \mathrm{H})$, $3.72(\mathrm{~s}, 3 \mathrm{H})$. 
2-(2,5-Dihydroxy-3,4-dimethoxy-phenyl)-cyclohex-1-enecarboxylic acid methyl ester (4c).

This compound was prepared from $\mathbf{3} \mathbf{c}$ using the same conditions as those used for the preparation of 4a. ${ }^{1} \mathrm{H}$ NMR $\left(\mathrm{CDCl}_{3}, 400 \mathrm{MHz}\right): \delta 6.36(\mathrm{~s}, 1 \mathrm{H}), 5.35(\mathrm{~s}, 1 \mathrm{H}), 5.19(\mathrm{~s}, 1 \mathrm{H})$, $3.93(\mathrm{~s}, 3 \mathrm{H}), 3.92$ (s, $3 \mathrm{H}), 3.51$ (s, 3H), 2.43 (t, $J=2.4 \mathrm{~Hz}, 2 \mathrm{H}), 2.33$ (t, $J=2.1 \mathrm{~Hz}, 2 \mathrm{H})$, $1.73(\mathrm{~m}, 4 \mathrm{H})$.

2-Hydroxy-3,4-dimethoxy-1-methyl-benzo[c]chromen-6-one (5a). Crude quinol 4a in $\mathrm{CDCl}_{3}$ was heated to $100^{\circ} \mathrm{C}$ in a sealed screwcap vial under argon. The reaction was periodically cooled to RT and the cyclization reaction was monitored by ${ }^{1} \mathrm{H}$ NMR (see Part II). After 7 days, the starting material was consumed and the crude reaction was purified by flash chromatography (10\% EtOAc/hexanes) to give coumarin $\mathbf{5 a}$ as a white solid (24mg, 84\%). ${ }^{1} \mathrm{H}$ NMR $\left(\mathrm{CDCl}_{3}, 400 \mathrm{MHz}\right): \delta 8.46(\mathrm{dd}, J=8.0 \mathrm{~Hz}, J=1.2 \mathrm{~Hz}, 1 \mathrm{H})$, $8.34(\mathrm{~d}, J=8.4 \mathrm{~Hz}, 1 \mathrm{H}), 7.57(\mathrm{dt}, J=7.6 \mathrm{~Hz}, J=1.6 \mathrm{~Hz}, 1 \mathrm{H}), 7.56(\mathrm{t}, J=7.6 \mathrm{~Hz}, 1 \mathrm{H}), 5.99$ (s, 1H), $4.10(\mathrm{~s}, 3 \mathrm{H}), 4.03$ (s, 3H), $2.70(\mathrm{~s}, 3 \mathrm{H}) .{ }^{13} \mathrm{C}$ NMR (100 MHz): $\delta 160.5,143.7$, $140.2,139.7,137.7,136.1,133.8,130.5,127.5,125.9,121.5,115.1,113.9,61.8,61.5$, 15.8. MS (LR-APCI): Calc'd for $\mathrm{C}_{16} \mathrm{H}_{14} \mathrm{O}_{5} 286.08$, measured 286.00.

2-Hydroxy-3,4-dimethoxy-benzo[c]chromen-6-one (5b). Crude quinol 4 b was cyclized as described above for the conversion of $\mathbf{4 a}$ to $\mathbf{5 a}$, except for the reaction temperature and time. After 6 days at RT the crude reaction was purified by flash chromatography (10\% EtOAc/hexanes) to give coumarin $\mathbf{5 b}$ as a white solid. ${ }^{1} \mathrm{H}$ NMR $\left(\mathrm{CDCl}_{3}, 300 \mathrm{MHz}\right): \delta 8.40(\mathrm{~d}, J=7.8 \mathrm{~Hz}, 1 \mathrm{H}), 7.96(\mathrm{~d}, J=8.1 \mathrm{~Hz}, 1 \mathrm{H}), 7.80(\mathrm{t}, J=7.2 \mathrm{~Hz}$, $1 \mathrm{H}), 7.56(\mathrm{t}, J=7.2 \mathrm{~Hz}, 1 \mathrm{H}), 7.35(\mathrm{~s}, 1 \mathrm{H}), 5.76(\mathrm{~s}, 1 \mathrm{H}), 4.10(\mathrm{~s}, 3 \mathrm{H}), 4.08(\mathrm{~s}, 3 \mathrm{H}).){ }^{13} \mathrm{C}$ NMR (100 MHz): $\delta 162.3,145.5,141.2,139.4,137.1,136.0,134.1,131.2,128.2,127.4$, 124.2, 115.0, 100.7, 61.9, 61.4. MS (LR-APCI): Calc'd for $\mathrm{C}_{15} \mathrm{H}_{12} \mathrm{O}_{5}$ 272.07, measured 272.16 .

2-Hydroxy-3,4-dimethoxy-7,8,9,10-tetrahydro-benzo[c]chromen-6-one (5c). Crude quinol $\mathbf{5 b}$ was cyclized as described above for the conversion of $\mathbf{4 a}$ to $\mathbf{5 a}$, except for the reaction temperature and time. After $58 \mathrm{hrs}$ at RT the crude reaction was purified by flash chromatography ( $10 \%$ EtOAc/hexanes) to give coumarin $\mathbf{5 b}$ as a white solid. ${ }^{1} \mathrm{H}$ NMR $\left(\mathrm{CDCl}_{3}, 400 \mathrm{MHz}\right): \delta 6.86(\mathrm{~s}, 1 \mathrm{H}), 5.68(\mathrm{~s}, 1 \mathrm{H}), 4.07(\mathrm{~s}, 3 \mathrm{H}), 4.03(\mathrm{~s}, 3 \mathrm{H}), 2.69(\mathrm{~m}, 2 \mathrm{H})$, $2.58(\mathrm{~m}, 2 \mathrm{H}), 1.82(\mathrm{~m}, 4 \mathrm{H}) .{ }^{13} \mathrm{C} \mathrm{NMR}\left(\mathrm{CDCl}_{3}, 100 \mathrm{MHz}\right): \delta 165,161,146.8,144.9$, 122.7, 116.3, 102.1, 99.5, 61.8, 61.6, 25.6, 24.2, 21.8, 21.6. MS (LR-APCI): Calc'd for $\mathrm{C}_{15} \mathrm{H}_{16} \mathrm{O}_{5} 276.10$, measured 272.16. 


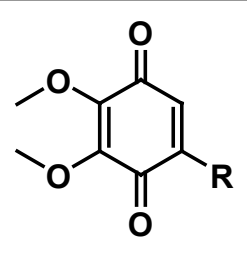

VII-X
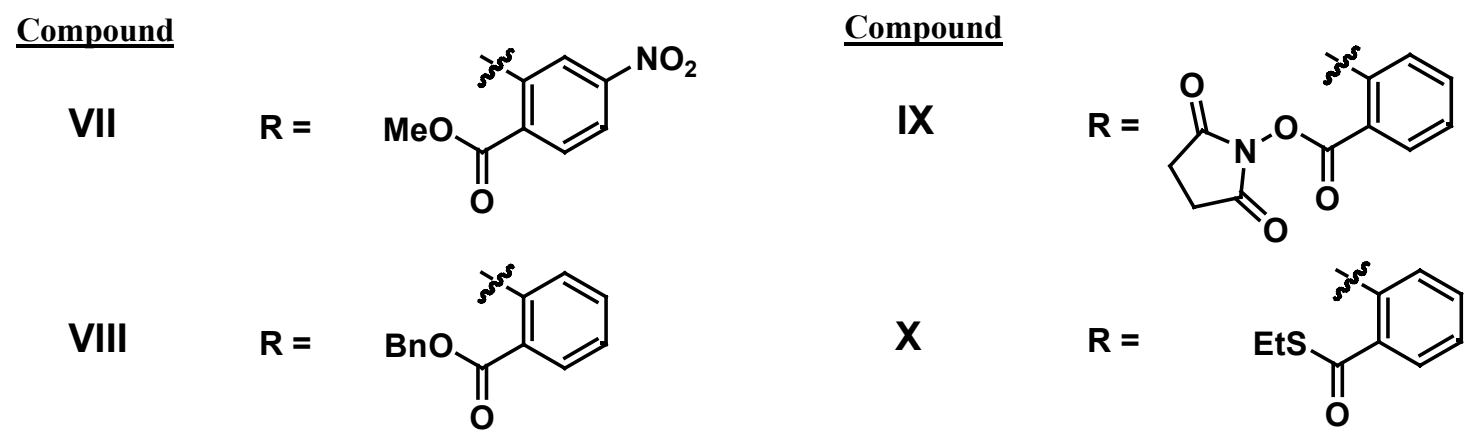

Scheme S5. Other variations of $\mathbf{3 b}, \mathbf{c}$ that were prepared (see Part II).

Compounds VII, VIII, IX, $\mathbf{X}$ (described in Part II) were prepared from boronic acid 1b using the same two step procedure as detailed above for the synthesis of $\mathbf{3 b}$, using the corresponding bromides in place of methyl 2-bromobenzoate: methyl 2-bromo-4nitrobenzoate $^{6}$ (VII), benzyl 2-bromobenzoate ${ }^{7}$ (VIII). Compounds IX and $\mathbf{X}$ were prepared by hydrogenolysis ${ }^{8}$ of VIII, followed by esterification with Nhydroxysuccinimide (IX) or ethanethiol (X) using standard coupling conditions. ${ }^{9}$ All compounds had ${ }^{1} \mathrm{H} /{ }^{13} \mathrm{C}$ NMR and MS that were consistent with their structures.

\footnotetext{
${ }^{6}$ Prepared from 2-bromo-4-nitrotoluene by oxidation [Bioorg. Med. Chem. 1999, 3011], followed by esterification with ethereal diazomethane.

${ }^{7}$ Prepared by esterification of 2-bromobenzoic acid with benzyl alcohol (1.1 eq), DCC (1.1 eq), DMAP (0.1 eq), $\mathrm{CH}_{2} \mathrm{Cl}_{2}, \mathrm{RT}$, 4hrs.

${ }^{8} 10 \%$ Pd-C, $\mathrm{H}_{2}(1 \mathrm{~atm}), \mathrm{MeOH}, \mathrm{RT}, 2 \mathrm{hrs}$.

${ }^{9} \mathrm{~N}$-hydroxysuccinimide (or ethanethiol) (1.1 eq), DCC (1.1 eq), DMAP (0.1 eq), $\mathrm{CH}_{2} \mathrm{Cl}_{2}, \mathrm{RT}, 4 \mathrm{hrs}$.
} 


\section{Part II: Lactonization}

\section{Protocol}

Lactonization in $\mathbf{C D C l}_{3}$. After reduction of quinones 3a-c (see Part I) ${ }^{10},{ }^{1} \mathrm{H}$ NMR spectra were taken periodically to monitor the transformation of quinols $4 \mathbf{a}-\mathbf{c}$ to coumarins 5a-c. The reactions were carried out in screw cap vials at RT or $100^{\circ} \mathrm{C}$ under argon, and spectra were taken at RT under argon (reactions at $100^{\circ} \mathrm{C}$ were cooled to RT before being transferred to the NMR tube).

Lactonization in $\mathbf{C D C l}_{3} /$ buffer. After reduction of quinone $\mathbf{3 c}$ (see Part I), the $\mathrm{CDCl}_{3}$ solution was combined with an equal volume of $50 \mathrm{mM}$ phosphate buffer $(\mathrm{pH} \mathrm{7.4)}$ and stirred vigorously at RT. Periodically, stirring was halted and a portion of the $\mathrm{CDCl}_{3}$ layer was removed and analyzed by ${ }^{1} \mathrm{H}$ NMR.

Lactonization in buffer. After reduction of quinone $3 \mathbf{c}$ (see Part I), the $\mathrm{CDCl}_{3}$ was removed by rotary evaporation and residual solvent was removed under high vacuum to give a clear oil which was kept under argon and diluted in DMSO- $d_{6} .{ }^{1} \mathrm{H}$ NMR of the DMSO- $d_{6}$ solution confirmed the presence of the quinol 4c. An aliquot $(10 \mu \mathrm{L})$ of the DMSO- $d_{6}$ solution was added to $50 \mathrm{mM}$ phosphate buffer $(\mathrm{pH} 7.4)(990 \mu \mathrm{L})$. Absorption and emission of this solution were immediately measured; UV-Vis and fluorescence spectra of this solution were consistent with formation of the coumarin, and simultaneous HPLC analysis corroborated its quantitative formation.

\section{Data Analysis}

Lactonization Rate Determination. Integration of ${ }^{1} \mathrm{H}$ NMR peaks corresponding to the quinols 4a-c and coumarins 5a-c was used to determine the rate of lactonization. In all cases, the conversion of quinol to coumarin was quantitative by the detection limits of ${ }^{1} \mathrm{H}$ NMR and no internal standard was used. Figure S1 shows three time-elapsed spectra from the cyclization rate determination of $\mathbf{4 c}$.

\footnotetext{
${ }^{10}$ it is important that the palladium catalyst is removed immediately after reduction is complete (red to colorless transition); prolonged exposure to palladium catalyst enhanced the rate of cyclization by about one order of magnitude.
} 
0 hrs [immediately after reduction]
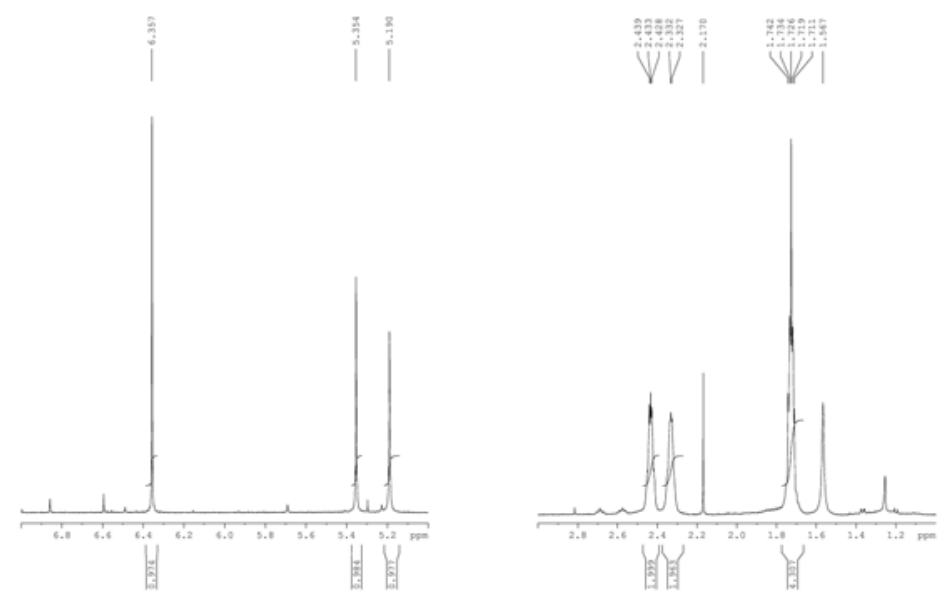

10hrs [60\% conversion]
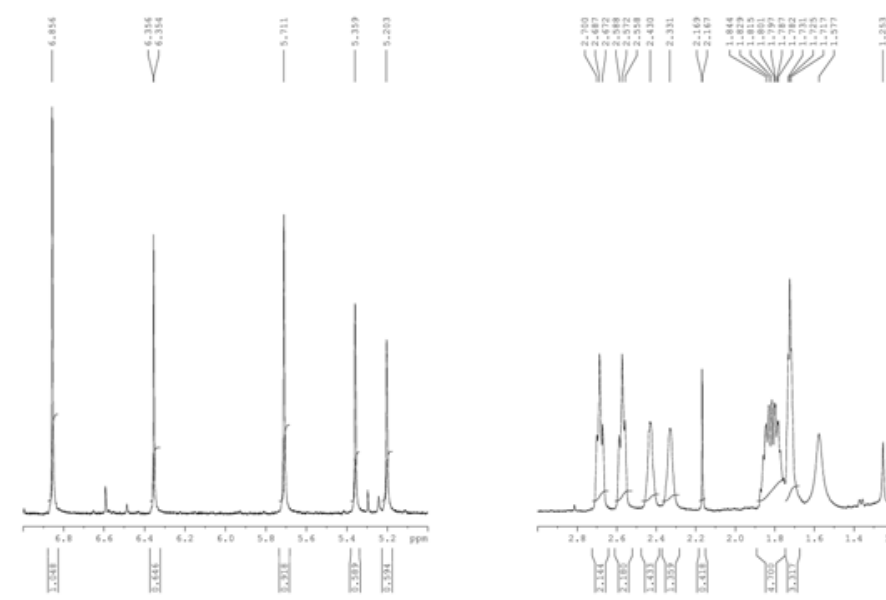

19hrs [77\% conversion]
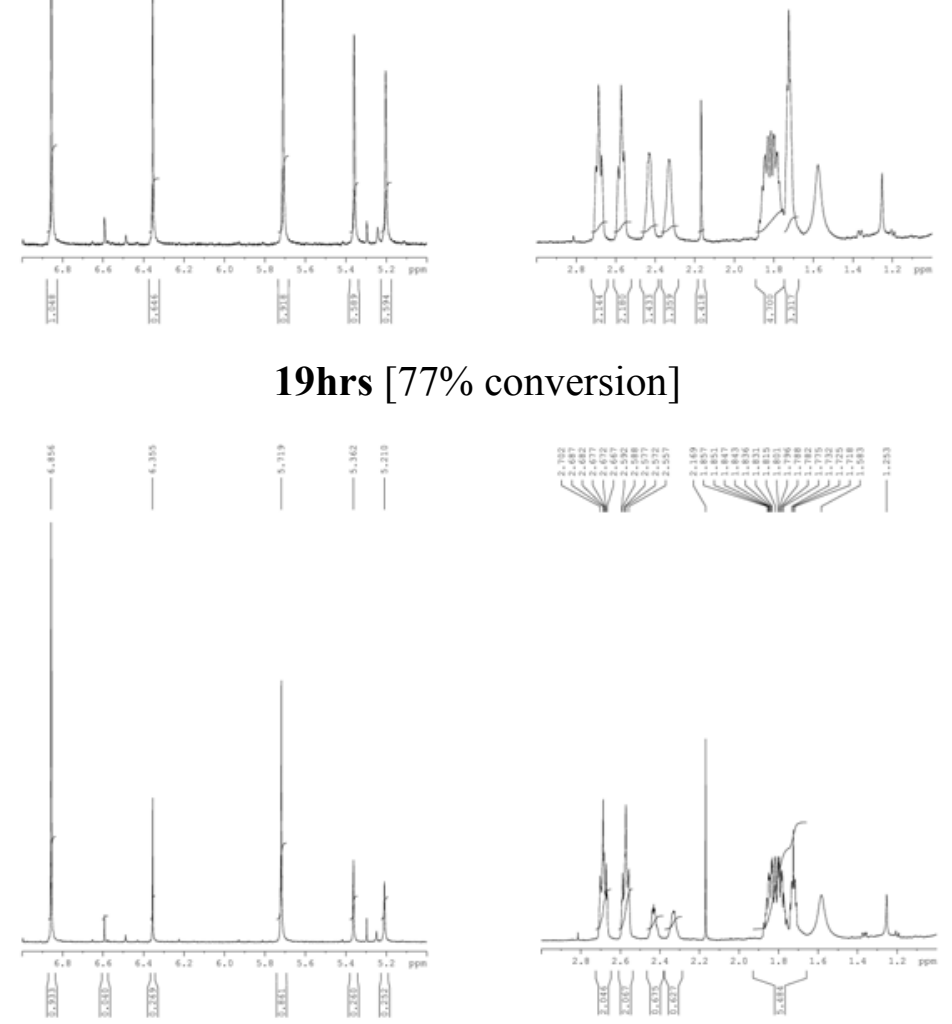

Figure S1. Time-elapsed ${ }^{1} \mathrm{H}$ NMR spectra of the conversion of $\mathbf{4 c}$ to $\mathbf{5 c}$. 
Since ${ }^{1} \mathrm{H}$ NMR showed quantitative conversion of $\mathbf{4}$ to $\mathbf{5}$, with no side reactions, the sum of the relative integrations of $\mathbf{4}$ and $\mathbf{5}$ was used as an internal standard to measure the decrease of [4]. The rate of lactonization obeyed first order kinetics, since a plot of $\ln [4]$ vs. time was linear for each substrate with good correlation coefficients.

\begin{tabular}{cccc} 
Substrate & $\mathbf{T}\left({ }^{\circ} \mathrm{C}\right)$ & $\boldsymbol{k}\left(10^{-3} \mathrm{~min}^{-1}\right)$ & $\mathbf{R}^{2}$ \\
\hline 4a & 100 & 0.29 & 0.96 \\
4b & 100 & 24.1 & 1.00 \\
4b & 25 & 0.17 & 0.99 \\
4c & 25 & 1.28 & 0.99 \\
VII & 25 & 0.07 & 0.99 \\
IX & 25 & 2.03 & 0.99 \\
X & 25 & 0.10 & 0.89
\end{tabular}

Table S1. Cyclization in $\mathrm{CDCl}_{3}$ of Various Quinol Derivatives.

\begin{tabular}{lcc} 
Solvent & $\boldsymbol{k}\left(10^{-3} \mathrm{~min}^{-1}\right)$ & $\mathbf{R}^{2}$ \\
\hline $\mathrm{CDCl}_{3}$ & 1.28 & 0.99 \\
$\mathrm{CDCl}_{3} /$ buffer & 36.6 & 0.97 \\
buffer & $>10^{4^{*}}$ & -
\end{tabular}

Table S2. Cyclization of $\mathbf{4 c}$ Various Solvent Systems. *not determined by ${ }^{1} \mathrm{H}$ NMR; approximated by assuming $90 \%$ conversion at 15 seconds. 


\section{Materials}

\section{Part III: Reduction Assays}

NADH was purchased from Sigma and stored at $4^{\circ} \mathrm{C}$; a fresh stock solution $(10 \mathrm{mM})$ in buffer was prepared prior to use and kept at $0^{\circ} \mathrm{C}$ throughout the assay (no longer than 4hrs). Dithiothreitol (DTT) and glutathione (GSH) were from Sigma and were kept at $4^{\circ} \mathrm{C}$; stock solutions $(10 \mathrm{mM})$ in buffer were prepared prior to use. $\mathrm{FeCl}_{2}$ from was used to prepare an aqueous stock solution of $\mathrm{Fe}^{\mathrm{II}}(10 \mathrm{mM})$. Riboflavin and dopamine were purchased from Aldrich and fresh stock solutions were prepared in DMSO (1 $\mathrm{mM}$ and $10 \mathrm{mM}$ respectively). Menaquinol, duroquinol, and ubiquinol were prepared fresh from the corresponding quinones (purchased from Aldrich) by catalytic hydrogenation in chloroform; the chloroform was removed and stock solutions in DMSO (10mM) were prepared before each assay. Unless otherwise noted, the buffer used contained $50 \mathrm{mM}$ phosphate, $10 \mu \mathrm{M}$ EDTA, $0.1 \mathrm{mg} / \mathrm{ml}$ Triton-X100, adjusted to $\mathrm{pH} 7.4$.

\section{Protocol}

Typical reactions were carried out with a final concentration of $100 \mu \mathrm{M}$ probe and $100 \mu \mathrm{M}$ /equivalent reductant, although it could be performed at concentrations as low as $30 \mu \mathrm{M}$ probe. An aliquot $(10 \mu \mathrm{L})$ of a stock solution of $3 \mathbf{c}(10 \mathrm{mM}$ in DMSO) was diluted in buffer to a final volume of $1 \mathrm{~mL}$ (final concentration $=10 \mu \mathrm{M}$ ) in a disposable plastic cuvette. An initial absorption spectrum was recorded. An aliquot $(10 \mu \mathrm{L}$ per equivalent) of a stock solution of the reductant was then added and the solution was agitated with a $1 \mathrm{~mL}$ pipet. Initial $(\mathrm{t}=<30 \mathrm{~s})$ and final $(\mathrm{t}=10 \mathrm{~min})$ absorbance spectra were then measured with no further agitation; in some cases, time-elapsed spectra were recorded. All reactions were carried out at RT in open air. All reductants showed no significant oxidation by air well beyond the time frame of the assay (at least 30min). [analogous assays carried out using fluorescence detection $\left(\lambda_{\text {exc }}=340 \mathrm{~nm}, \lambda_{\mathrm{em}}=550 \mathrm{~nm}\right)$ at typical concentrations of $50 \mu \mathrm{M}$ probe, or as low as $10 \mu \mathrm{M}$ probe]

\section{Data Analysis}

Approximate rates were determined by measuring the increase in absorbance at $330 \mathrm{~nm}$ (formation of 5c), except in the cases of NADH (decrease in absorbance at 340nm), and menaquinol (increase in absorbance at 270nm). The magnitude of the change in absorbance intensity after a $10 \mathrm{~min}$ incubation time was used to assign a qualitative extent of reduction (see Figure 3, text). For selected reductants, the reaction was monitored at time points (see Figure 4, text). 
Part IV: ${ }^{1} \mathrm{H}$ NMR for 3a-c, 4a-c, 5a-c.

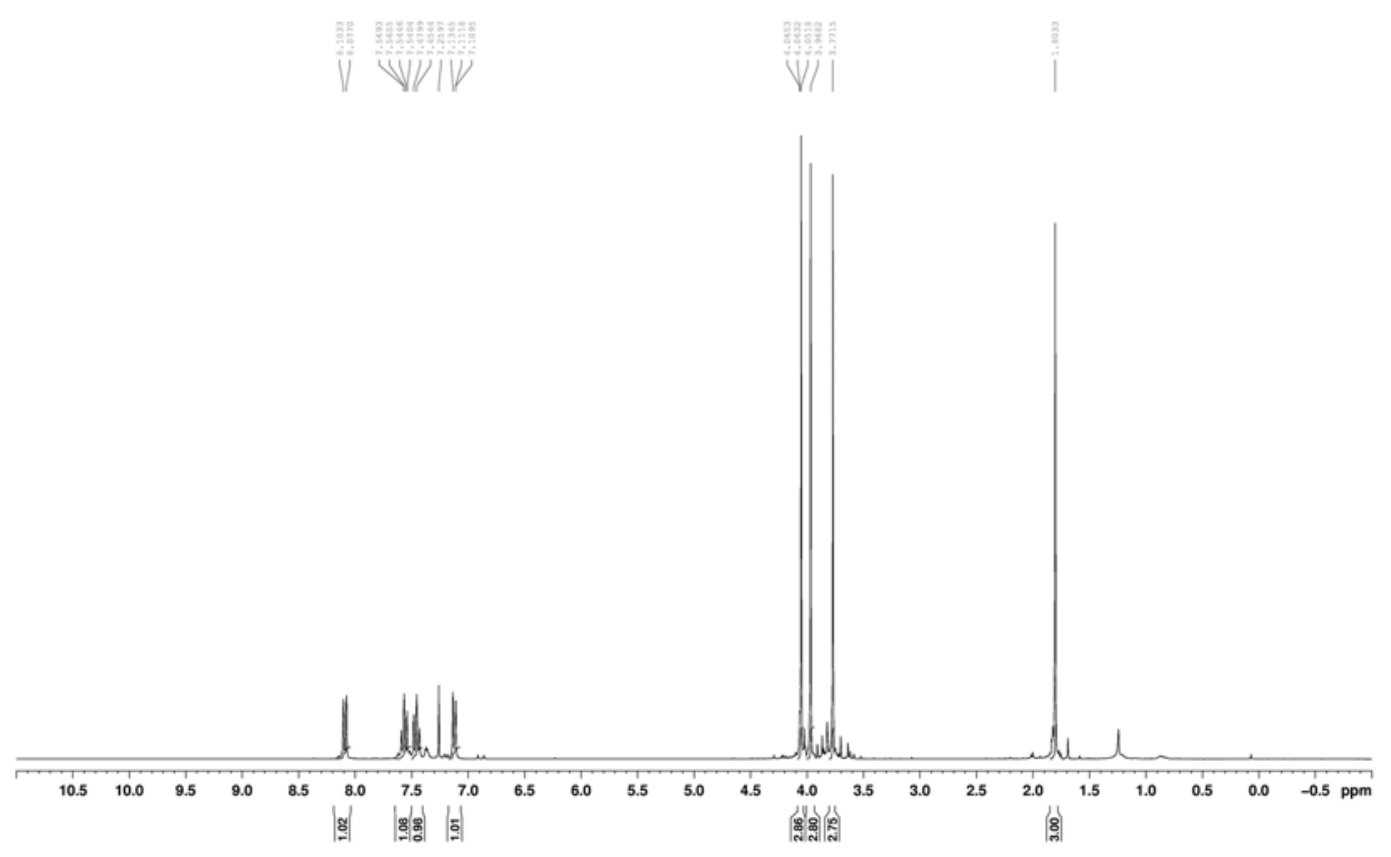

Quinone 3a 


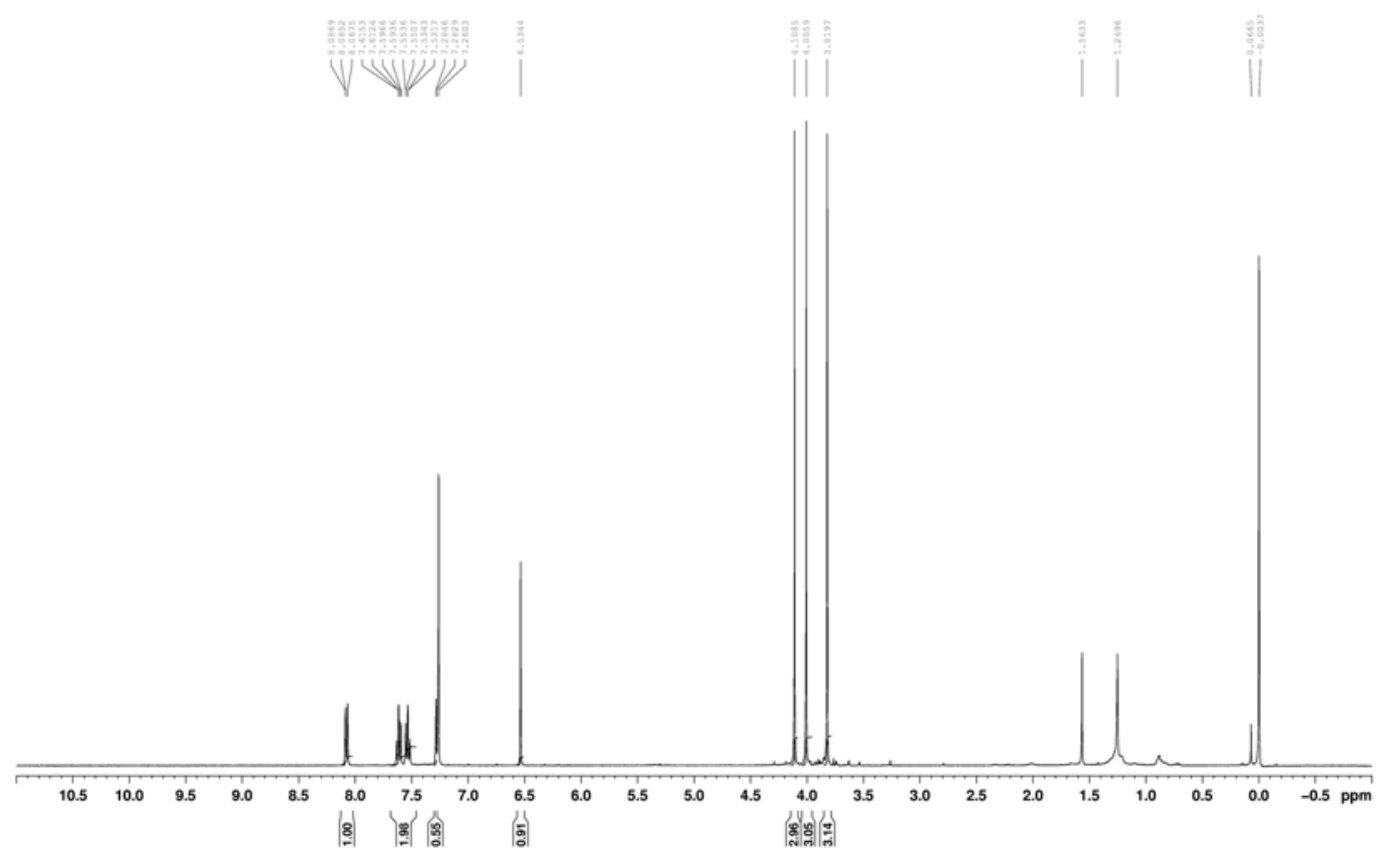

Quinone 3b

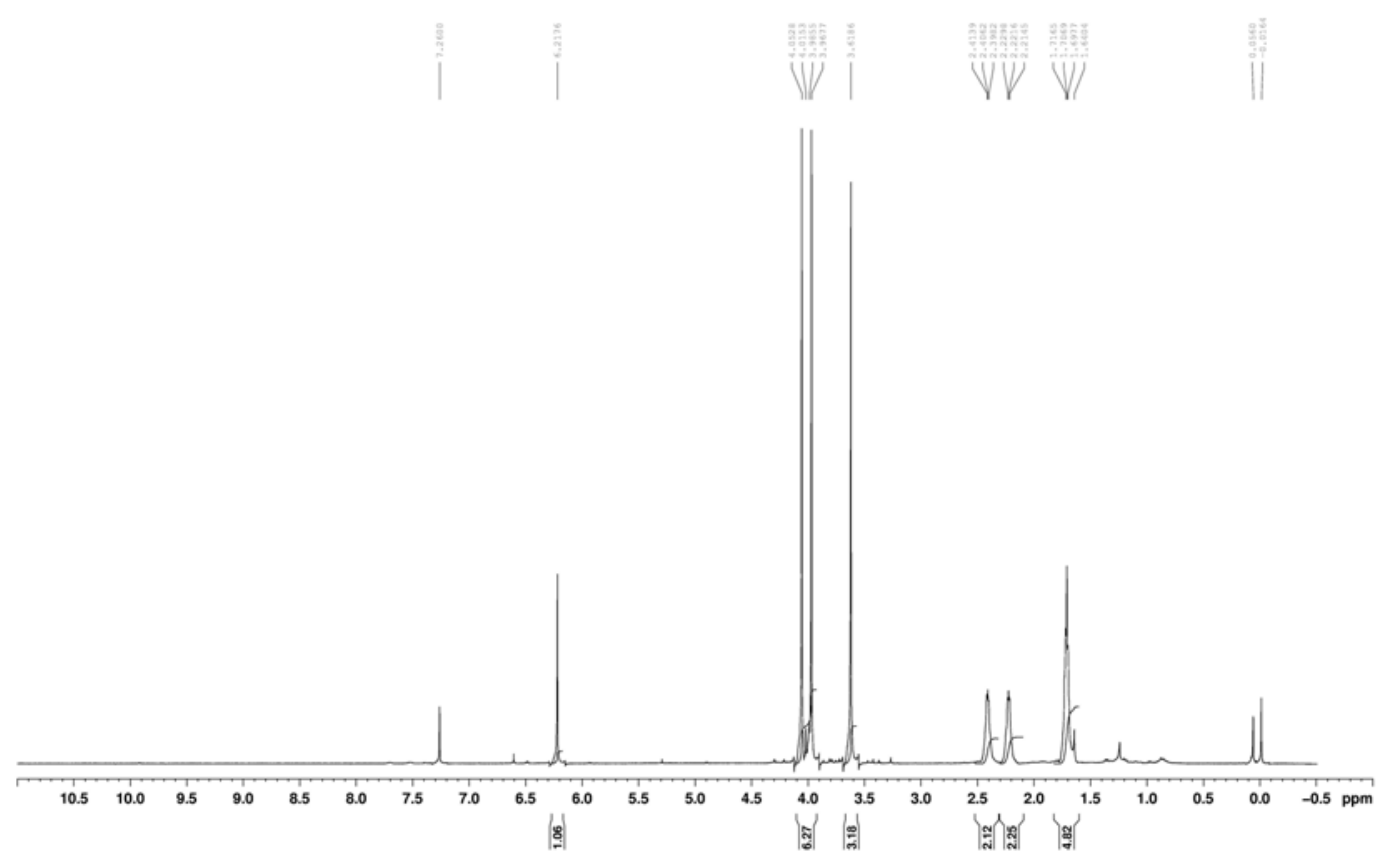

Quinone 3c 


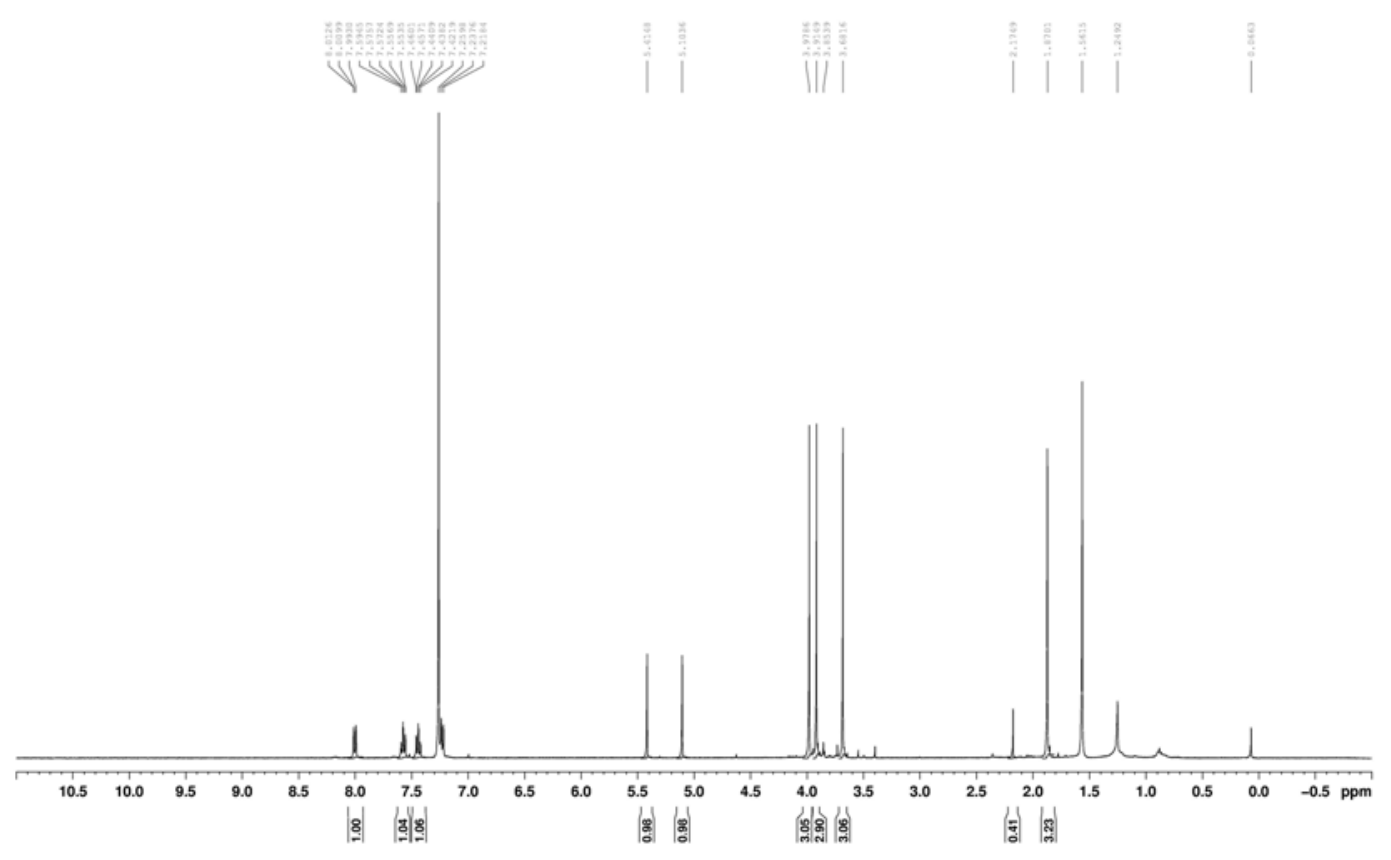

Quinol 4a

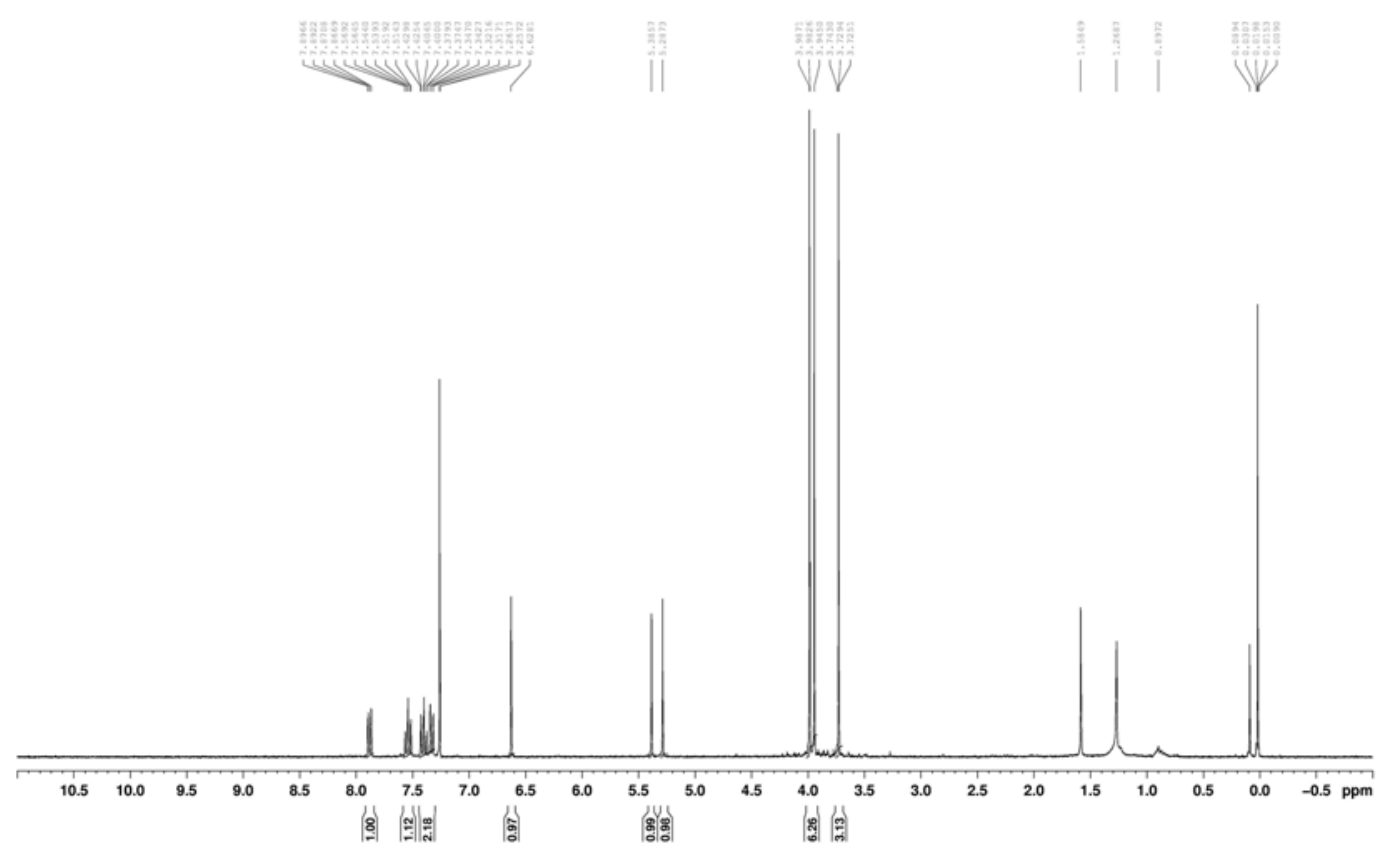

Quinol 4b 


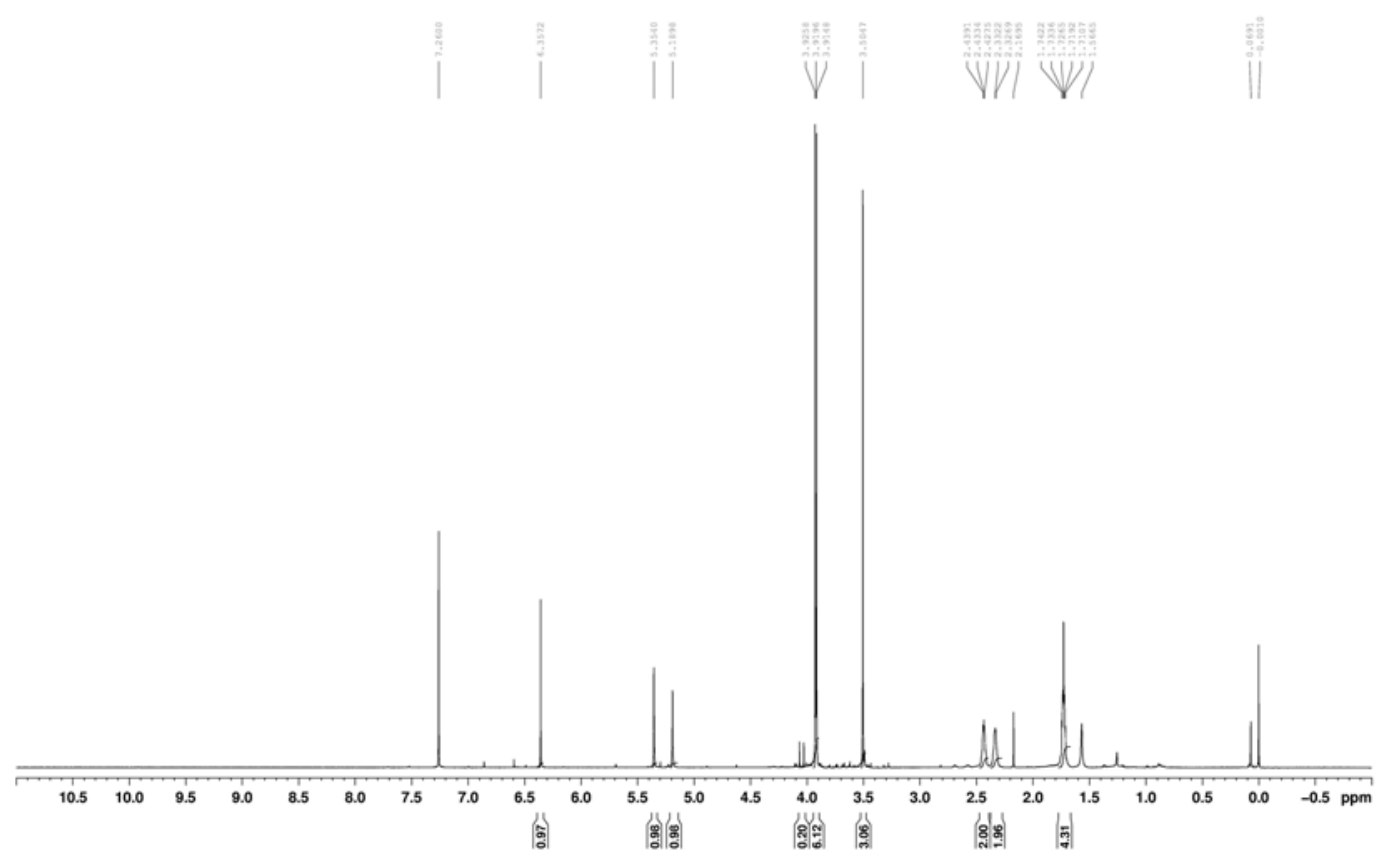

Quinol 4c

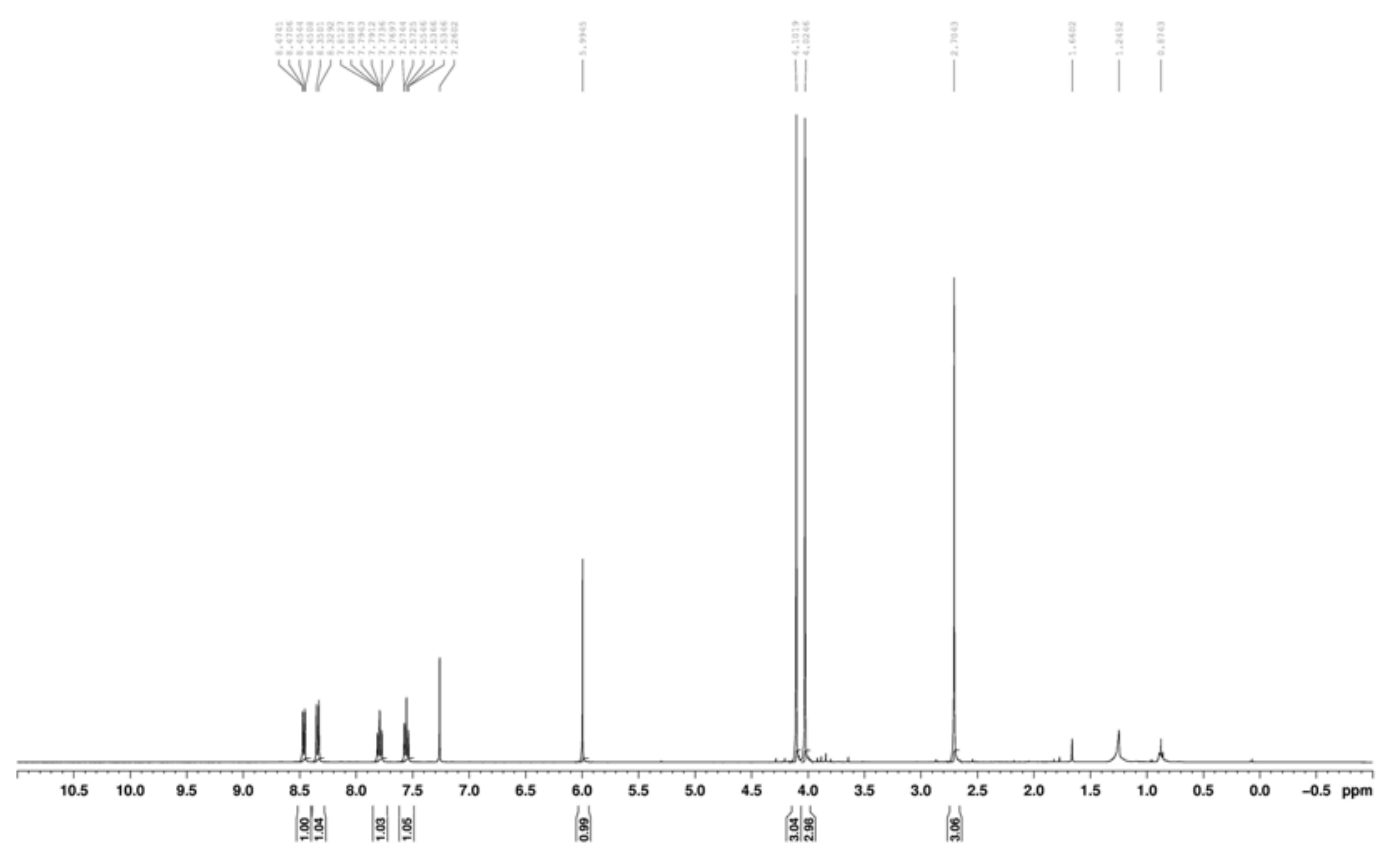

Coumarin 5a 


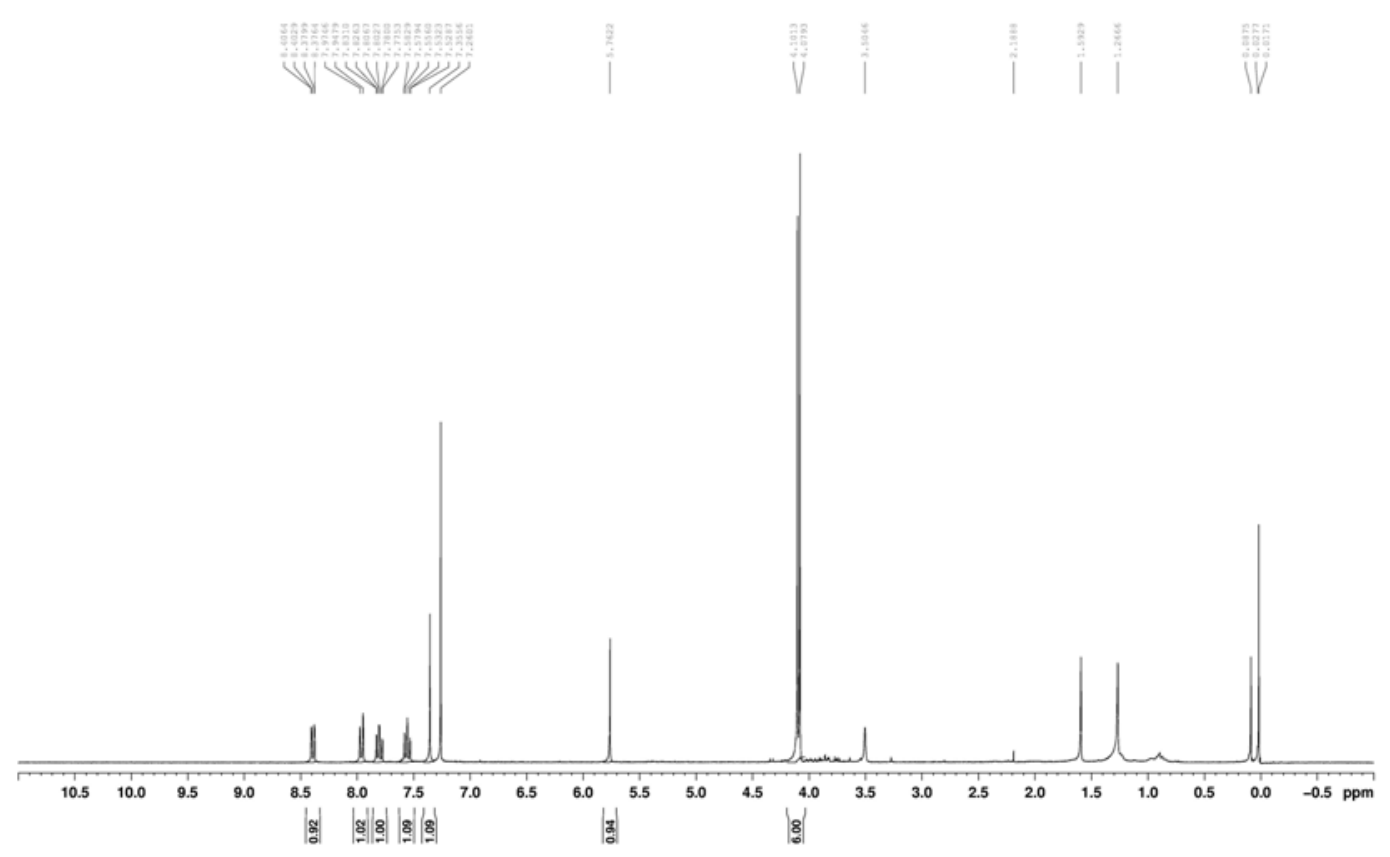

Coumarin 5b

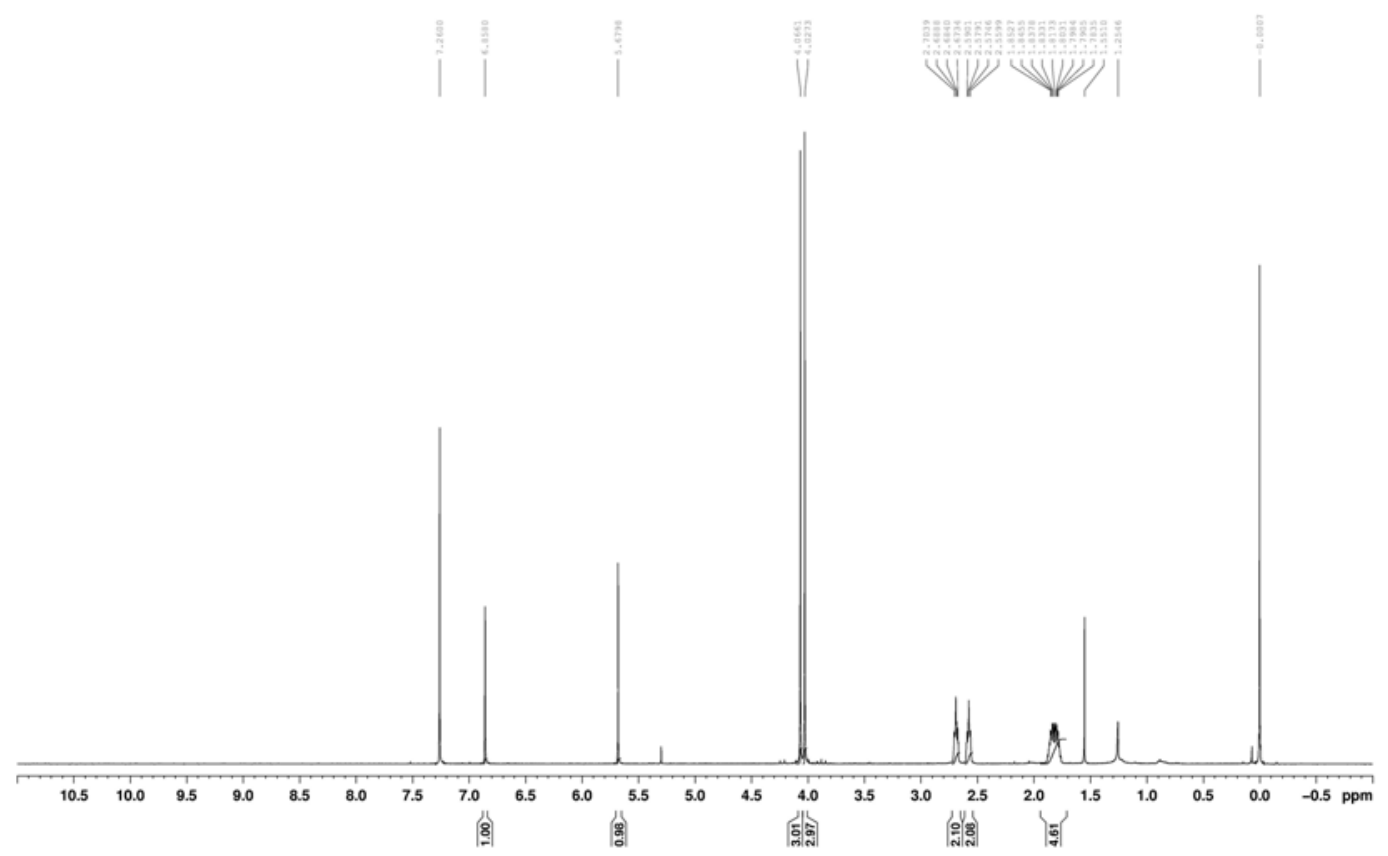

Coumarin 5c 


\section{Part V: Selected Photophysical Data for Coumarins 5a-c}

\section{General}

As noted in the text, coumarins 5a-c were weakly fluorescent compounds. When compared to the commonly referenced standard diphenylanthracene (DPA), these compounds had $<1 \%$ quantum yield. For our purposes, this finding deemed the accurate measurement of the quantum yield difficult and not useful. As expected, emission of coumarin $\mathbf{5 c}$ showed some sensitivity to solvent polarity and $\mathrm{pH}$. Quinone $\mathbf{3 c}$ showed no emission. Below are selected spectra for compounds $\mathbf{3 c}$ and 5c. [all spectra taken at 100 $\mu \mathrm{M}$; SDS = sodium dodecyl sulfate; $\mathrm{pH} 5$ and 7 50mM phosphate; $\mathrm{pH} 950 \mathrm{mM}$ glycine].

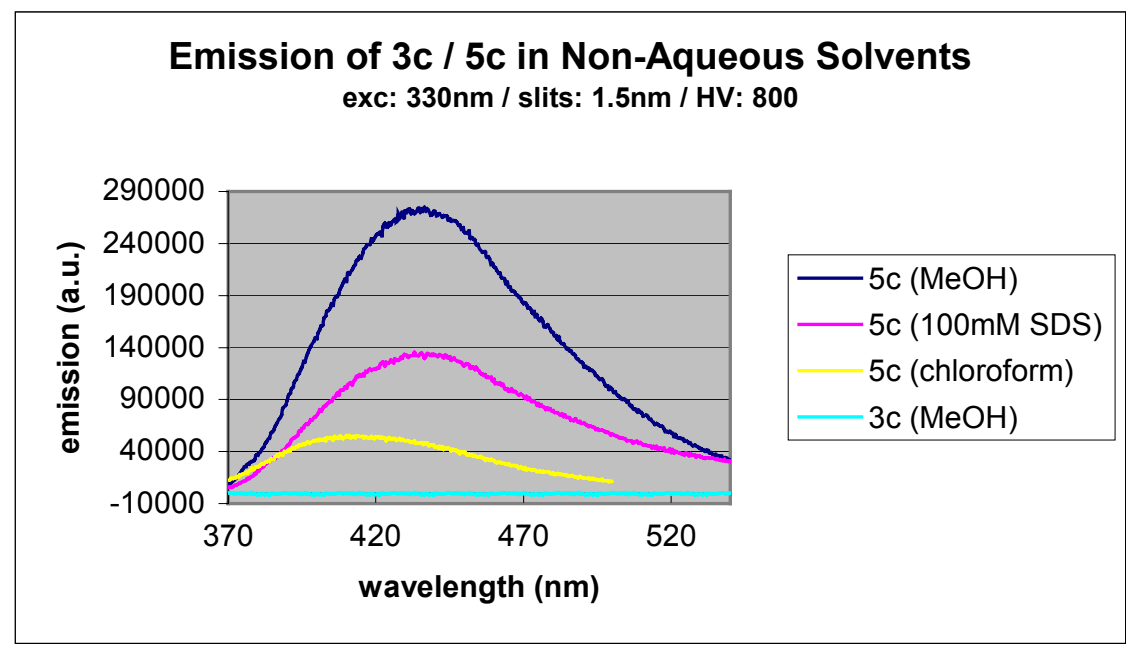




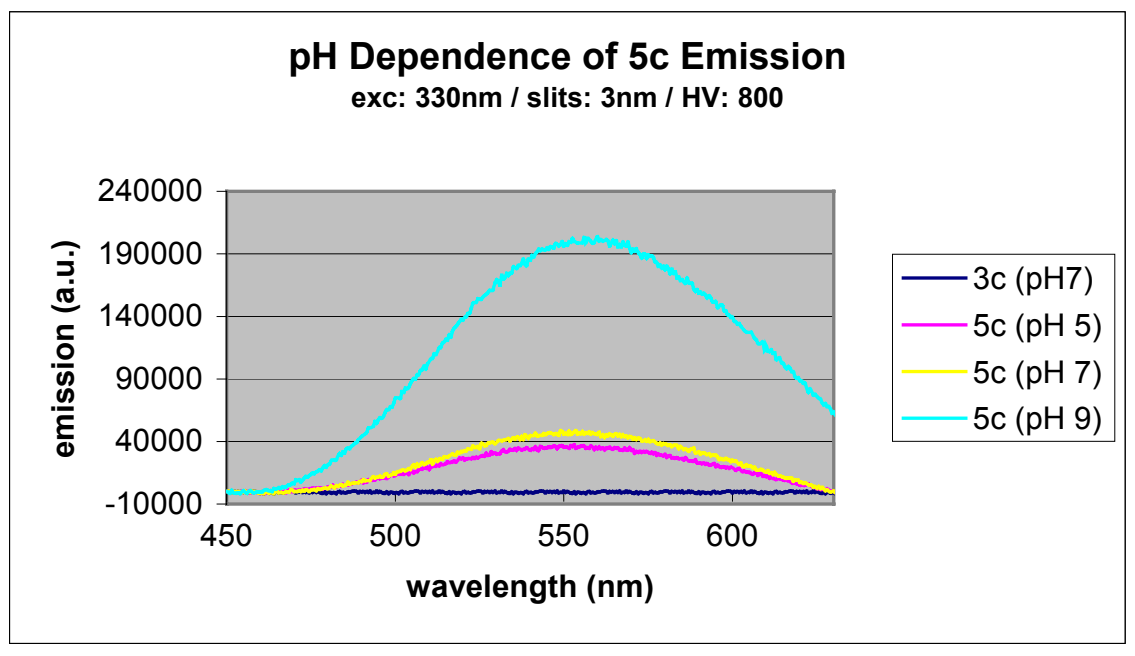

